\title{
Frequency-Dependent Modulation of Retinogeniculate Transmission by Serotonin
}

\author{
Daniel P. Seeburg, ${ }^{1}$ Xiaojin Liu, ${ }^{2}$ and Chinfei Chen ${ }^{2}$ \\ ${ }^{1}$ MD-PhD Program, Harvard Medical School, and 2Division of Neuroscience, Children's Hospital Boston, Harvard Medical School, Boston, Massachusetts \\ 02115
}

The relay of visual information converging in the lateral geniculate nucleus (LGN) en route to the visual cortex is modulated by projections from brainstem nuclei. The release of serotonin, one mediator of these effects, has been shown to act at a presynaptic site to inhibit neurotransmitter release at the retinogeniculate synapse, the connection between retinal ganglion cells and thalamocortical relay neurons in the LGN. To understand how serotonergic inhibition of synaptic transmission influences the transfer of information at this

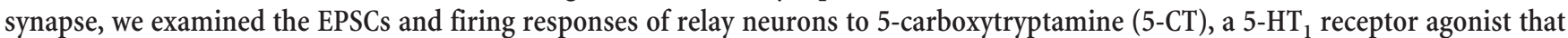
preferentially activates the presynaptic over postsynaptic modulatory effects of serotonin. Bath application of 5-CT inhibits synaptic strength, relieves synaptic depression, and reduces the total synaptic charge transferred at the retinogeniculate synapse in mouse LGN brain slices. In contrast, 5-CT does not significantly alter the membrane potential response of relay neurons to trains of intracellular current injections. Here we show that presynaptic serotonergic modulation results in a frequency-dependent inhibition of relay neuron firing. At low-frequency stimulation, 5-CT markedly reduces charge transfer at the retinogeniculate synapse, thus inhibiting relay neuron firing. However, inhibition of firing by 5-CT is diminished during high-frequency stimulation, because relief from synaptic depression partially offsets the reduction in charge transfer. Thus, presynaptic serotonergic inhibition plays a powerful role in modulating the frequency range of visual information transmitted via the retinogeniculate synapse such that high-frequency inputs are more reliably transmitted than low-frequency inputs.

Key words: serotonin; thalamus; visual system; presynaptic modulation; high-pass filter; sleep

\section{Introduction}

Visual information, encoded in the firing patterns of retinal ganglion cells (RGCs), is modified in the dorsal lateral geniculate nucleus (LGN) by a number of factors that include brainstem neuromodulatory inputs, intrinsic inhibitory connections, corticothalamic feedback circuitry, and short-term synaptic plasticity (McCormick and Bal, 1994; Steriade et al., 1997; Chen et al., 2002). For example, during varying states of arousal or attention, brainstem inputs release a variety of neurotransmitters that modify the firing response of relay neurons by altering intrinsic membrane conductance (McCormick, 1992a). More recently, we have shown that robust presynaptic modulation can also occur at retinal axon terminals to alter both the strength and short-term plasticity of the retinogeniculate synapse (Chen and Regehr, 2003).

One neurotransmitter shown to modulate both presynaptic and postsynaptic aspects of the retinogeniculate synapse is serotonin. This neuromodulator is released in the LGN by projections from the dorsal raphe nucleus in the brainstem (De Lima and

Received Sept. 9, 2004; revised 0ct. 22, 2004; accepted 0ct. 22, 2004.

This work was supported by National Institutes of Health (NIH) Grant T32GM07753-24 to D.P.S. and NIH Grants K08 NS02056 and R01 EY013613 to C.C. We thank B. Hooks, E. Edson, I. Raman, R. Born, J. Assad, and D. Ferster for helpful suggestions on this manuscript.

Correspondence should be addressed to Chinfei Chen, Division of Neuroscience, Children's Hospital Boston, 300 Longwood Avenue, Boston, MA 02115. E-mail: chinfei.chen@childrens.harvard.edu.

DOI:10.1523/JNEUROSCI.3749-04.2004

Copyright $\odot 2004$ Society for Neuroscience ～0270-6474/04/2410950-13\$15.00/0
Singer, 1987; Papadopoulos and Parnavelas, 1990; Dinopoulos et al., 1995). Activation of postsynaptic serotonergic receptors results in a rightward shift of the voltage dependence of the hyperpolarization-activated cation current, $I_{\mathrm{h}}$. This depolarizes relay neurons by $1-3 \mathrm{mV}$ and abolishes spontaneous rhythmic burst firing in individual relay neurons. Serotonin is thus thought to contribute to the activation of thalamocortical neurons during the transition from slow-wave sleep to awake states (McCormick and Pape, 1990a; McCormick, 1992b; Monckton and McCormick, 2002).

In contrast, several studies have shown that either iontophoretic application of serotonin to the LGN or stimulation of the dorsal raphe nucleus leads to inhibition of both spontaneous and evoked firing of relay neurons (Yoshida et al., 1984; Marks et al., 1987; Kayama et al., 1989). Consistent with these studies, we have shown that activation of presynaptic serotonergic receptors inhibits action potential (AP)-evoked calcium influx into retinal axon terminals, decreasing neurotransmitter release and short-term synaptic depression (Chen and Regehr, 2003). These inhibitory effects seem counterintuitive, given that the release of serotonin from dorsal raphe neurons is high during awake states and decreases during sleep states (McGinty and Harper, 1976; Lydic et al., 1983; GuzmanMarin et al., 2000). This raises the question of how a significant inhibition of synaptic transmission can be reconciled with the apparent necessity for precise transfer of visual information during awake states. 
To understand the function of presynaptic serotonergic inhibition, we examined the effects of serotonin at the retinogeniculate synapse in LGN brain slices. We found that presynaptic serotonergic modulation of this synapse occurred primarily through $5-\mathrm{HT}_{1 \mathrm{~B}}$ receptors $\left(5-\mathrm{HT}_{1 \mathrm{~B}} \mathrm{Rs}\right)$, resulting in inhibition of synaptic release and relief of synaptic depression. Moreover, the 5- $\mathrm{HT}_{1}$ receptor agonist 5-carboxytryptamine (5-CT) was relatively selective in activating presynaptic over postsynaptic serotonergic receptors at the retinogeniculate synapse. In experiments that correlated the EPSC response to the firing of the postsynaptic relay neuron, we found that, although reduction of synaptic strength by 5-CT had an overall inhibitory effect on relay neuron firing, inhibition in response to low-frequency stimulation $(<20 \mathrm{~Hz})$ was significantly greater than for high-frequency stimulation $(100-200 \mathrm{~Hz})$. Thus, presynaptic serotonergic modulation narrows the frequency range of information transmitted at the retinogeniculate synapse.

\section{Materials and Methods}

Slice preparation. Parasagittal brain slices containing both the optic tract and the dorsal lateral geniculate nucleus were obtained from p23-32 Black Swiss mice (Taconic, Germantown, NY) as described previously (Chen et al., 2002). Briefly, the brain was quickly removed and immersed into an oxygenated $4^{\circ} \mathrm{C}$ choline-based cutting solution containing the following (in mM): $87 \mathrm{NaCl}, 25 \mathrm{NaHCO}_{3}, 37.5$ choline chloride, 25 glucose, $2.5 \mathrm{KCl}, 1.25 \mathrm{NaH}_{2} \mathrm{PO}_{4}, 7 \mathrm{MgCl}_{2}$, and $0.5 \mathrm{CaCl}_{2}$. The brain tissue was then mounted on the cutting stage of a vibratome (Leica VT1000S; Leica, Nussloch, Germany) and submerged into oxygenated $4^{\circ} \mathrm{C}$ cutting solution. Slices $(250 \mu \mathrm{m})$ were allowed to recover for $30 \mathrm{~min}$ at $30^{\circ} \mathrm{C}$ in an oxygenated choline-based cutting solution and then for another $30 \mathrm{~min}$ at $30^{\circ} \mathrm{C}$ in oxygenated saline containing the following (in $\mathrm{mM}$ ): $125 \mathrm{NaCl}$, $26 \mathrm{NaHCO}_{3}, 1.25 \mathrm{NaH}_{2} \mathrm{PO}_{4}, 2.5 \mathrm{KCl}, 1 \mathrm{MgCl}_{2}, 2 \mathrm{CaCl}_{2}$, and 25 glucose.

Electrophysiology. Whole-cell voltage-clamp synaptic recordings from geniculate neurons were obtained using glass pipettes (1.2-1.5 M $\Omega$ ) filled with an internal solution consisting of the following (in $\mathrm{mm}$ ): 35 CsF, $100 \mathrm{CsCl}, 10$ EGTA, 10 HEPES, 0.1 methoxyverapamil, pH 7.4. This solution was designed to minimize the contributions from postsynaptic intrinsic membrane conductances and second messenger systems. The bath saline solution contained the $\mathrm{GABA}_{\mathrm{A}}$ receptor antagonist bicuculline $(20 \mu \mathrm{M}$; Sigma, St. Louis, $\mathrm{MO})$ and the $\mathrm{GABA}_{\mathrm{B}}$ receptor antagonist (2S)-3-[[(1S)-1-(3,4-dichlorophenyl)ethyl] amino-2-hydroxypropyl] (phenylmethyl) phosphinic acid (CGP55845; Tocris Cookson, Ballwin, $\mathrm{MO})$ in experiments involving trains.

Voltage-clamp recordings of $I_{\mathrm{h}}$ and synaptic responses to trains of stimuli as well as current-clamp recordings were obtained using glass pipettes (2.0-3.0 M $\Omega$ ) containing the following internal solution (in mM): $116 \mathrm{KMeSO}_{4}, 6 \mathrm{KCl}, 2 \mathrm{NaCl}, 20$ HEPES, 0.5 EGTA, 4 MgATP, 0.3 NaGTP, $10 \mathrm{NaPO}_{4}$ creatine, pH 7.25, with KOH. $I_{\mathrm{h}}$ current amplitude measurements were obtained by subtracting the current in the presence of [4-( $N$-ethyl- $N$-phenylamino)-1,2-dimethyl-6(methylamino)pyrimidinium chloride (ZD7288; a selective blocker of $I_{\mathrm{h}}$ currents) from the total current. Differences in $I_{\mathrm{h}}$ current amplitude in response to 5-CT was measured $3.0 \mathrm{sec}$ after the holding potential was stepped from -50 to $-100 \mathrm{mV}$ to obtain the maximal current amplitude change in the presence of the modulator.

The optic tract was stimulated using a pair of pulled glass electrodes filled with saline in a bipolar configuration. Stimulus intensities ranged from 5 to $40 \mu \mathrm{A}$ (duration, $0.15-0.25 \mathrm{msec}$ ). As described previously, we found that each relay neuron was innervated by one to three retinal inputs, often with one strong input $(>700 \mathrm{pA})$ and one to two smaller inputs ( $<300 \mathrm{pA})$ (Chen and Regehr, 2000). When possible, the response to the strong single-fiber stimulation was obtained by first stimulating at subthreshold intensity and then incrementally increasing the intensity in $0.25 \mu \mathrm{A}$ steps until the minimal stimulation that elicited a synaptic response was found (Chen et al., 2002). In some cases, during trains of stimulation at $34-36^{\circ} \mathrm{C}$, additional inputs were recruited. In these cases, the stimulus intensity was increased so that the stimulation of all of the fibers was reliable during the trains of varying frequencies.

Current-clamp recordings were initially achieved in voltage-clamp mode to find the retinal fiber input to the cell. Once a reliable synaptic response could be elicited with retinal fiber stimulation, recordings were changed to the current-clamp $\left(I_{\text {fast }}\right)$ mode of the Axopatch $200 \mathrm{~B}$ or the I-Clamp mode of the Multiclamp 700A (Axon Instruments, Foster City, CA) to examine the firing response to the same presynaptic stimulation. The firing pattern, acquired from a retinal ganglion cell in response to a flash of light, was kindly provided by Dr. Sheila Nirenberg (University of California Los Angeles, Los Angeles, CA). Experiments addressing the frequency dependence of serotonergic inhibition were performed using randomized, interleaved stimulation trains at frequencies of 10, 20, 50, 100 , and $200 \mathrm{~Hz}$ both with and without a conditioning stimulation train at $50 \mathrm{~Hz}$. Reliable stimulation of the retinal fibers was checked in voltageclamp mode at the beginning and the end of the experiment (see Fig. $6 \mathrm{~A}$ ). EPSC amplitudes during trains of stimuli were measured as the difference between the peak EPSC current and the baseline current immediately after the stimulus artifact. In the case of stimulation trains that followed five conditioning stimuli at $50 \mathrm{~Hz}$, analysis of synaptic charge and EPSC amplitude did not include the synaptic responses to the first five stimuli. The decay of the last EPSC in a train $\left(\right.$ EPSC $\left._{15}\right)$ was fit by the double exponential function $A+B^{\star} \exp \left(x / \tau_{\mathrm{f}}\right)+C^{\star} \exp \left(x / \tau_{\mathrm{s}}\right)$, where $\tau_{\mathrm{f}}$ and $\tau_{\mathrm{s}}$ are the fast and slow time constants, respectively. Synaptic charge ( $Q$ ) was calculated by integrating the evoked synaptic current.

Current injections to examine the postsynaptic membrane potential response were designed to mimic EPSPs of $2-5 \mathrm{mV}$ in amplitude by ramping from a peak current of $100-500$ to $0 \mathrm{pA}$ over a duration of $1 \mathrm{msec}$.

Stock solutions of pharmacological agents such as 5-CT, 3- $((R)-2-$ carboxypiperazine-4-yl)-propyl-1-phosphonic acid, anpirtoline (ANP), (士)8-hydroxy-2-dipropylaminotetralin hydroxybromide (8-hydroxyDPAT), $\alpha$-methyl-5-HT ( $\alpha$-Met 5-HT), cinanserin, and ZD7288 (all from Tocris Cookson) were stored at $-20^{\circ} \mathrm{C}$ and diluted $1: 1000$ to $1: 5000$ into the bath reservoir immediately before application. Stock solutions of cyanopindolol and nonyloxytryptamine were dissolved in DMSO and diluted 1:1000 for the final concentration. Bath application of 1:1000 DMSO did not alter synaptic transmission. Constant bath flow during application of drugs was ensured by a perfusion pump (Gilson Medical Electric, Middleton, WI) at flow rates of $2-4 \mathrm{ml} / \mathrm{min}$. Dead space in the perfusion tubing was reduced to $1 \mathrm{ml}$, allowing rapid bath exchange of pharmacological agents.

Data acquisition and analysis. Recordings from both current-clamp and voltage-clamp experiments were acquired with an Axopatch 200B or Multiclamp 700A amplifier (Axon Instruments) filtered at $1 \mathrm{kHz}$ and digitized at $10-20 \mathrm{kHz}$ with an ITC-16 interface (InstruTech, Port Washington, NY). Data analysis was performed using Igor software (WaveMetrics, Lake Oswego, OR). The voltage threshold for action potential firing was measured as the membrane potential at which the $\mathrm{dV} / \mathrm{dt} \geq 10$ $\mathrm{Vsec}^{-1}$. Data are summarized as mean \pm SEM, and statistics were calculated using the two-tailed Student's $t$ test (paired, where indicated) and ANOVA, where indicated.

\section{Results}

\section{Serotonergic effects at the retinogeniculate synapse}

We recorded from the retinogeniculate synapse from freshly prepared LGN brain slices of p23-32 Black Swiss mice in recording conditions that isolate the excitatory connection between the retina and thalamus from the inhibitory and cortical feedback circuitry (see Materials and Methods). The relatively few and robust inputs that each relay neuron receives during this late stage in development allowed us to reproducibly stimulate only one to three retinal inputs (Chen and Regehr, 2000). Figure $1 A$ illustrates the modulatory effects of the $5-\mathrm{HT}_{1}$ receptor agonist, 5-CT, on the response to paired retinal fiber stimulation at the retinogeniculate synapse. On average, $50 \mathrm{~nm}$ 5-CT significantly decreased the amplitude of the peak AMPA receptor (AMPAR) and NMDA receptor (NMDAR) EPSC by $55.7 \pm 10.2 \%(n=5 ; p<$ 

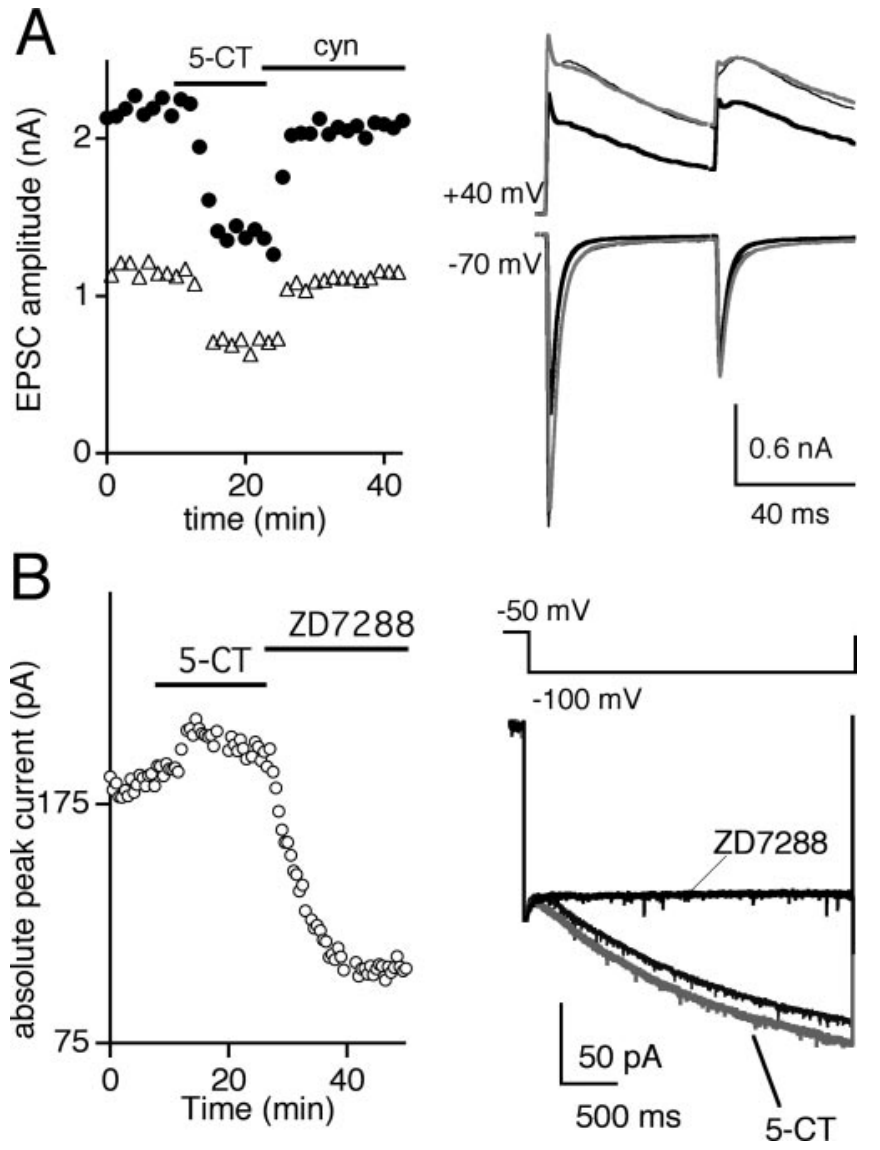

Figure 1. Activation of $5-\mathrm{HT}_{1}$ serotonergic receptors reversibly reduces glutamatergic transmission. A, Presynaptic effects of $5-\mathrm{HT}_{1}$ activation are monitored by recording from geniculate neurons using a (sF-based internal solution. Time course of the absolute peak EPSC amplitude of the AMPAR- (circles) and NMDAR- (triangles) mediated synaptic currents (left) and representative current traces (right) are shown in control conditions (thin traces), during bath application of $50 \mathrm{~nm} 5-\mathrm{CT}$ (black traces) and during washout in the presence of $5 \mu \mathrm{m}$ cyanopindolol (gray traces). Peak NMDAR current amplitudes were measured $10 \mathrm{msec}$ after the onset of outward synaptic current measured at a holding potential of $+40 \mathrm{mV}$, whereas AMPAR currents were approximated as the peak inward current elicited at a holding potential of $-70 \mathrm{mV}$. B, The postsynaptic effects of $5-\mathrm{HT}_{1}$ receptor activation on the $I_{\mathrm{h}}$ current in geniculate neurons are monitored using a KCl-based internal recording solution. Left, The time course of the absolute peak current of the hyperpolarization-activated current (measured at 3 sec after hyperpolarization); right, the average current traces in control conditions during bath application of 5-СТ (50 nм; gray trace) and ZD7288 (10 $\mu$ m; black trace). Capacitance transients are blanked for clarity. Black bars indicate the timing and duration of drug application. Bath temperature, $24-26^{\circ} \mathrm{C}$.

0.005 , paired $t$ test $)$ and $58 \pm 8.2 \%(n=5 ; p<0.005$, paired $t$ test), respectively (Chen and Regehr, 2003). The changes in peak amplitude are plotted over time in control conditions during bath application of $50 \mathrm{nM} 5$-CT and during washout of 5-CT in the presence of the $5-\mathrm{HT}_{1}$ receptor antagonist cyanopindolol (Fig. 1A, left). As shown previously, bath application of 5-CT reduced the peak amplitude of the EPSC and alleviated shortterm synaptic depression, consistent with a presynaptic site of modulation (Chen and Regehr, 2003). The paired-pulse ratio (PPR), measured as the percentage ratio of the peak amplitude of the second EPSC (A2) to the first EPSC (A1) in AMPAR currents, significantly increased from $29 \pm 3 \%$ in control conditions to $68 \pm 11 \%$ for an interstimulus interval (ISI) of $50 \mathrm{msec}(n=5$; $p=0.02$, paired $t$ test), underscoring the strong relief from depression in the presence of 5-CT. Bath application of the 5- $\mathrm{HT}_{1}$ receptor antagonist cyanopindolol (cyn) reversed the inhibition of synaptic strength by 5 -CT to $84 \pm 5$ and $87 \pm 3 \%$ of control for
AMPAR and NMDAR EPSC, respectively, and reduced PPR to $44 \pm 7 \%(p<0.03 ; n=5$ for AMPAR and NMDAR EPSC amplitude and PPR; 5-CT vs cyn).

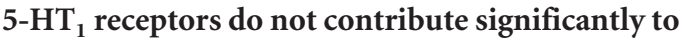 postsynaptic serotonergic modulation}

Previous studies have demonstrated that serotonergic modulation of the hyperpolarization-activated current, $I_{\mathrm{h}}$, in thalamic relay neurons results in depolarization of the cell (Pape and McCormick, 1989; McCormick and Pape, 1990b). However, the specific 5-HT receptor subtype that mediates this effect in relay neurons has not been identified. To evaluate whether 5- $\mathrm{HT}_{1}$ receptors contribute to this postsynaptic response in addition to their role in presynaptic inhibition, we examined the effects of 5-CT on $I_{\mathrm{h}}$ in LGN neurons using an internal recording solution that is potassium based and contains a regenerative solution with ATP and GTP (see Experimental procedures). Unlike the CsFbased internal solution used for EPSC recordings (Figs. 1 A, 2) that are designed to minimize the known postsynaptic effects of 5-HT, the $\mathrm{K}^{+}$-based solution used for these experiments also permits modulation of intrinsic relay neuron conductances. Figure $1 B$ shows the $I_{\mathrm{h}}$ current, elicited by hyperpolarizing from -50 to $-100 \mathrm{mV}$, in control conditions and during bath application of 5-CT (gray trace). This hyperpolarization-activated current was inhibited by the $I_{\mathrm{h}}$ channel inhibitor ZD7288. On average, $50 \mathrm{~nm}$ 5-CT enhanced the ZD7288-sensitive current to $119 \pm 5 \%$ of control ( $n=7$ cells; $p=0.002$, paired $t$ test). However, the 5-CT-mediated effect on $I_{\mathrm{h}}$ current did not significantly alter the membrane potential (average resting membrane potential in control conditions, $-79 \pm 1 \mathrm{mV}$, vs in the presence of $5-\mathrm{CT},-80 \pm 2 \mathrm{mV}, n=10, p=0.4$, paired $t$ test, and a change of $-2.6 \pm 1.1 \mathrm{mV}$ from an initial holding membrane potential of $-55 \mathrm{mV}, n=8, p=0.3)$. Therefore, activation of $5-\mathrm{HT}_{1}$ receptors appears to have a larger presynaptic effect on synaptic transmission when compared with its postsynaptic effect on membrane potential. By using the selective $5-\mathrm{HT}_{1}$ receptor agonist 5 -CT, we could study the role of presynaptic serotonergic modulation on the relay of visual information in isolation from the postsynaptic effects of serotonin.

\section{Pharmacological characterization of presynaptic serotonergic modulation}

Several serotonin receptor subtypes have been identified in the thalamus, including $5-\mathrm{HT}_{1 \mathrm{~A}}, 5-\mathrm{HT}_{1 \mathrm{~B}}, 5-\mathrm{HT}_{2 \mathrm{~A}}, 5-\mathrm{HT}_{2 \mathrm{C}}$, and 5- $\mathrm{HT}_{7}$ (Boschert et al., 1994; Pompeiano et al., 1994; Gustafson et al., 1996; Kia et al., 1996; Gerard et al., 1997; Steriade et al., 1997; Sari et al., 1999; Upton et al., 1999; Lopez-Gimenez et al., 2001a,b). To determine which of these receptor subtypes mediate serotonergic modulation at a presynaptic site of the retinogeniculate connection, we took advantage of various 5 -HT receptor agonists and antagonists. The robust effects of $5-\mathrm{HT}_{1}$ receptor agonist and antagonist, 5-CT and cyanopindolol, respectively, at the retinogeniculate synapse suggested the involvement of this subclass of receptors. To distinguish between $5-\mathrm{HT}_{1 \mathrm{~A}}$ and $5-\mathrm{HT}_{1 \mathrm{~B}}$ receptors, we first examined the effects $5 \mu \mathrm{M}$ 5-nonyloxytryptamine (5-NOT), an agonist with higher selectivity for the $5-\mathrm{HT}_{1 \mathrm{~B}}$ over the $5-\mathrm{HT}_{1 \mathrm{~A}}$ receptor (Glennon et al., 1996). Nonyloxytryptamine $(5 \mu \mathrm{M})$ significantly inhibited the peak amplitude of evoked EPSCs to $48.8 \pm 7.5 \%$ of control $(n=$ 4 ; $p<0.05$, paired $t$ test) (Fig. $2 A$ ). Another selective $5-\mathrm{HT}_{1 \mathrm{~B}}$ agonist, ANP (5 $\mu \mathrm{M})$ (Schlicker et al., 1992), also inhibited synaptic strength to $58.9 \pm 3.5 \%$ of control $(n=4 ; p<0.05$, paired $t$ test) (Fig. $2 D$ ). In contrast, bath application of 8 -hydroxy- 

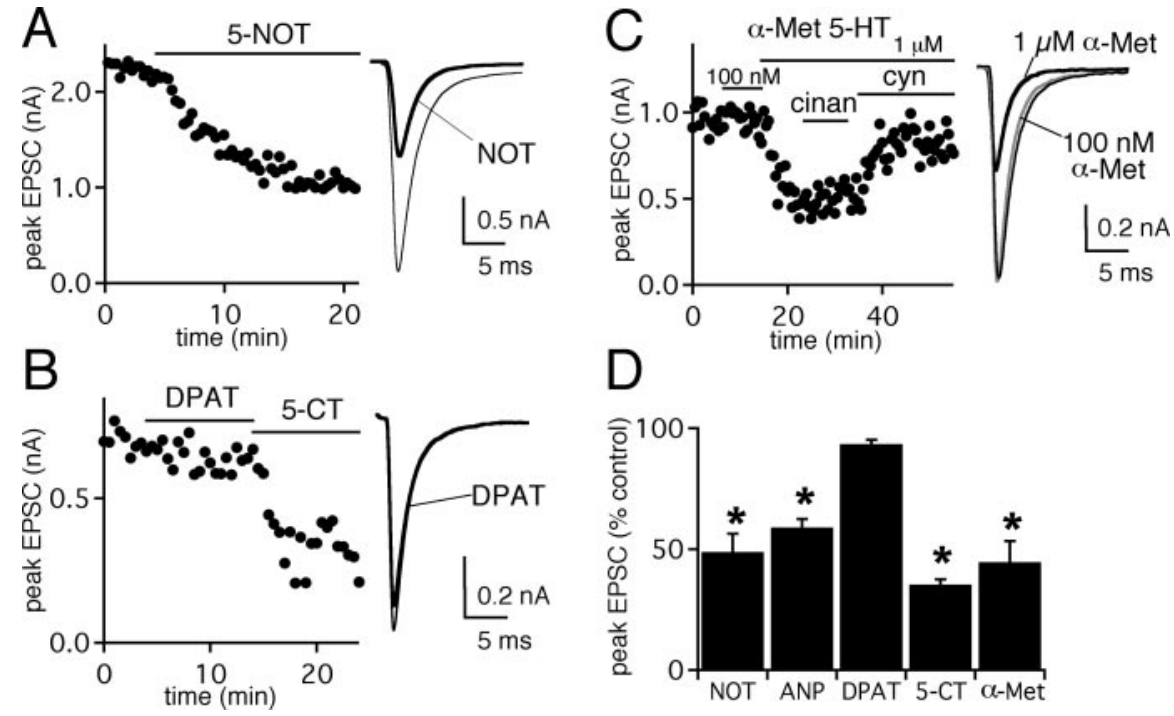

Figure 2. Retinogeniculate presynaptic modulation is mediated through $5-\mathrm{HT}_{1 \mathrm{~B}}$ receptors. $A-\mathrm{C}$, The effects of $5-\mathrm{HT}_{1 \mathrm{~B}}$ receptor agonist 5-NOT $(5 \mu \mathrm{M})(A), 5-\mathrm{HT}_{1 \mathrm{~A}}$ receptor agonist 8-hydroxy-DPAT (DPAT; $\left.1 \mu \mathrm{M}\right)(B)$, and 5-HT 2 receptor agonist $\alpha$-Met 5-HT $(100 \mathrm{~nm}$ and $1 \mu \mathrm{M})(C)$. Left, EPSC peak amplitudes are plotted against time during control conditions and during application of serotonergic agonists and antagonists, as indicated. The black bars indicate duration of drug application. Right, Averaged EPSC traces are shown during control conditions (thin trace) and in the presence of serotonergic agonists [black trace(s)]. C, At the right, $1 \mu \mathrm{m}$ (black trace) but not $100 \mathrm{~nm}$ (gray trace) $\alpha$-Met 5-HT decreased synaptic strength. All traces are the average of $8-10$ trials. Recordings were performed using the (sF-based internal solution to examine presynaptic effects. D, Summary of agonist-induced changes in peak EPSC amplitude relative to that in control conditions. NOT, $n=4$ cells; ANP (5-HT 1 agonist), $n=4$ cells; DPAT, $n=3$ cells; 5 -CT ( $50 \mathrm{nM}), n=5$ cells; $\alpha$-Met, $n=4$ cells. Error bars indicate \pm SEM. The asterisk over the bar indicates that average amplitude in the presence of applied agent is significantly different than without agent ( $p<0.05$; paired $t$ test). Bath temperature, $24-26^{\circ} \mathrm{C}$.

DPAT $(1 \mu \mathrm{M})$, a highly selective $5 \mathrm{HT}_{1 \mathrm{~A}}$ agonist $\left(>10^{4}\right.$-fold greater affinity over $5 \mathrm{HT}_{1 \mathrm{~B}}$ receptors) that also activates $5-\mathrm{HT}_{7}$ receptors $\left(\mathrm{pK}_{\mathrm{D}}=6.6\right)$ (Middlemiss and Fozard, 1983; Engel et al., 1986; Wood et al., 2000), had little effect on the synaptic current (inhibited to $93.4 \pm 1.7 \%$ of control; $n=3 ; p=0.08$, paired $t$ test) when compared with EPSCs in the presence of 5-CT (inhibited to $35.3 \pm 2 \%$ of control, $n=5, p<0.005$ ) (Fig. $2 B$ ).

$5-\mathrm{HT}_{2}$ receptors have also been shown to act as mediators of serotonergic modulation in the thalamus, in particular by causing excitation of local inhibitory interneurons (McCormick and Wang, 1991). To test whether $5-\mathrm{HT}_{2}$ receptors contribute to the presynaptic actions of serotonin on the excitatory retinogeniculate input, we examined the effects of $\alpha$-methyl-5-HT, a broad $5-\mathrm{HT}_{2}$ receptor agonist, in the presence of the $\mathrm{GABA}_{\mathrm{A}}$ receptor antagonist bicuculline (Richardson et al., 1985; Baxter et al., 1995). As shown in Figure $2 C$, at a concentration of $100 \mathrm{~nm}$, we observed no effect on the peak amplitude of evoked EPSCs. At a higher concentration $(1 \mu \mathrm{M})$, however, the peak amplitude was significantly inhibited to $44.7 \pm 8.7 \%$ of control $(n=4 ; p<0.01$, paired $t$ test). Because $\alpha$-methyl-5-HT has only $\sim 1.3$-fold specificity at 5- $\mathrm{HT}_{2}$ over $5-\mathrm{HT}_{1 \mathrm{~B}}$ receptors (Engel et al., 1986; Baxter et al., 1995), it is conceivable that the drug elicited its effect by cross-reacting with other serotonergic receptors. To address this possibility, we applied, in succession, the specific $5-\mathrm{HT}_{2} \mathrm{R}$ antagonist cinanserin $(25 \mu \mathrm{M})$ and the specific $5-\mathrm{HT}_{1} \mathrm{R}$ antagonist cyanopindolol $(5 \mu \mathrm{M})$ to the bath solution. Figure $2 C$ shows that cyanopindolol, but not cinanserin, antagonized the effect elicited by $\alpha$-methyl-5-HT, consistent with $\alpha$-methyl-5-HT mediating its effect through $5-\mathrm{HT}_{1}$ receptors. A summary of the average effects of different 5-HT receptor agonists on the peak EPSC amplitude is shown in Figure $2 D$. Together, our pharmacological data support the role of $5-\mathrm{HT}_{1 \mathrm{~B}}$ receptor-mediated inhibition of synaptic transmission at the retinogeniculate synapse. We found that the effects of 5-CT on the retinogeniculate synapse were more easily reversible than 5-NOT; thus, we chose to use 5-CT for our subsequent experiments studying presynaptic serotonergic modulation.

\section{Presynaptic serotonergic inhibition relieves paired-pulse depression} To further understand the role of relief of synaptic depression by presynaptic serotonergic modulation on the transmission of visual information, we examined in more detail the effect of 5-CT on the synaptic response to trains of retinal fiber stimulation. First, we examined the synaptic response to pairs of stimuli. Figure $3 A$ shows the effects of 5-CT on the recovery from synaptic depression for pairs of EPSCs separated by ISIs varying from 10 to $200 \mathrm{msec}$. 5-CT greatly alleviated paired-pulse depression, particularly for short ISIs. For example, the paired-pulse ratio significantly increased from $20 \pm 2 \%$ for an ISI of $20 \mathrm{msec}$ in control conditions to $83 \pm$ $4 \%(n=5 ; p<0.01$, paired $t$ test $)$ in the presence of 5-CT ( $50 \mathrm{~nm})$. A summary plot of the recovery from synaptic depression with and without 5-CT (open squares and filled circles, respectively) as a function of ISI is shown in Figure 3B. 5-CT was effective in relieving synaptic depression for pairs of stimuli separated by up to $1 \mathrm{sec}$ in time (PPR for ISI 1 sec: control, $73 \pm 2 \%$, vs 5 -CT, $84 \pm 3 \%$; $n=5 ; p=$ 0.01 , paired $t$ test). Comparison of the second EPSC amplitude of the synaptic response in the presence of 5-CT to the corresponding EPSC amplitude without the serotonergic agonist $\left(\mathrm{EPSC}_{\mathrm{CT}} /\right.$ EPSC $_{\mathrm{CONT}}$ ) revealed an enhancement of synaptic strength up to $\sim 150 \%$ of control at short ISIs (Fig. $3 C$ ). These findings suggest that activation of presynaptic serotonergic receptors could significantly alter the synaptic response over a wide range of presynaptic firing frequencies.

\section{5- $\mathrm{HT}_{1}$ receptor modulation during physiological stimulation} Given the strong relief from synaptic depression that followed presynaptic modulation with 5-CT, we next examined how this would affect synaptic transmission under more physiological conditions by recording the synaptic response to trains of retinal fiber stimuli at a bath temperature of $34-36^{\circ} \mathrm{C}$. Figure 4 (left) shows the representative traces before (top) and during (bottom) bath application of $50 \mathrm{~nm} 5-\mathrm{CT}$ for $10 \mathrm{~Hz}(A), 100 \mathrm{~Hz}(B)$, and $200 \mathrm{~Hz}(C)$ retinal fiber stimulation. On the right, the average control (black) and 5-CT (gray) traces are overlaid so that the relative amplitudes of each EPSC after the first EPSC in the train $\left(\right.$ EPSC $\left._{2-15}\right)$ can be compared. At all frequencies tested, 5-CT decreased the synaptic strength of the first EPSC. However, at higher frequencies $(>50 \mathrm{~Hz})$, the amplitudes of subsequent AMPAR EPSCs, which under control conditions were subject to strong depression (observe control traces in Fig. $4 B, C$ ), were enhanced, consistent with our studies using pairs of stimuli (Fig. 3 ). The effects of 5-CT on the EPSC amplitudes during a train of 15 stimuli are summarized in Figure $4 D$. The amplitude of each EPSC $_{\mathrm{N}}$ in a train in the presence of 5-CT, normalized to the 


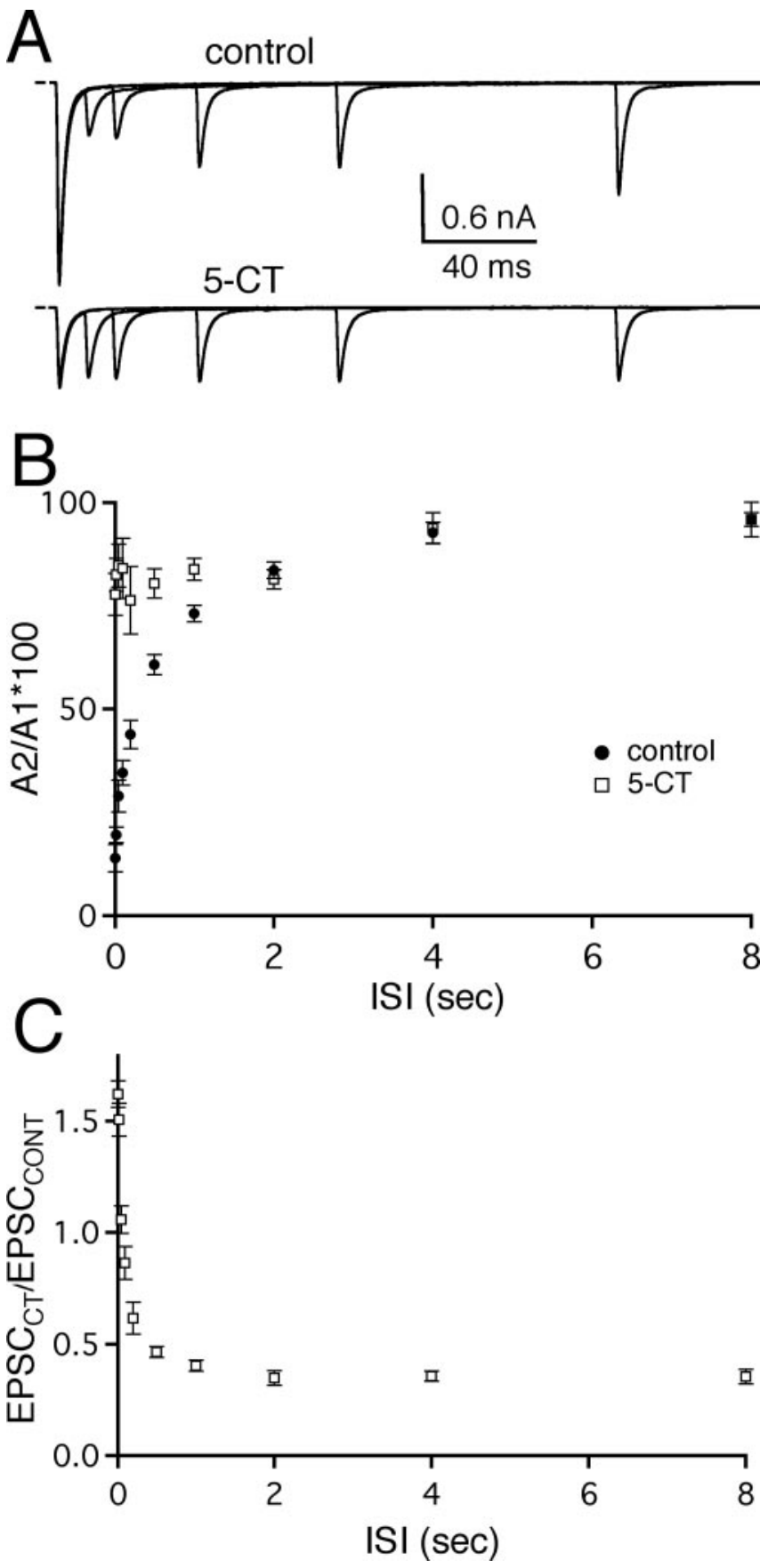

Figure 3. Serotonergic receptor activation alters short-term plasticity at the retinogeniculate synapse. A, 5-CT relieved synaptic depression especially for short ISIs. Superimposed pairs of AMPAR EPSCs recorded at varying ISIs were acquired under control conditions (top) and in the presence of $5-\mathrm{CT}$ ( $50 \mathrm{~nm}$; bottom). Traces are the average of three to five trials. $B$, The average percentage ratio of the second (A2) to the first (A1) EPSC amplitude is plotted versus ISI for control conditions (filled circles; $n=5$ cells) and in the presence of 5 -CT (open squares; $n=5$ cells). ANOVA revealed significant differences in the PPR of 5 -CT versus control ( $p \ll 0.0001)$ and significant interaction between ISI and recovery from depression ( $p \ll 0.0001)$. C, The absolute amplitude of the second EPSC in response to pairs of stimuli is enhanced by 5-CT at short ISIs. The second EPSC amplitude in the presence of 5-CT is plotted relative to that in control conditions ( EPSC $_{\mathrm{CT}} / \mathrm{EPSC}_{\mathrm{CONT}}$ ) as a function of short ISIs. Data represent the mean $\pm \mathrm{SEM}$. Bath temperature, $24-26^{\circ} \mathrm{C}$.

corresponding EPSC $_{\mathrm{N}}$ amplitude in control conditions was plotted as a function of stimulus number. We found that in the presence of 5-CT, all EPSCs in a train decreased in strength at 10 and $20 \mathrm{~Hz}$ ( $p \leq 0.02$, paired $t$ test). In contrast, 5-CT significantly increased the EPSC amplitude in response to the 2nd-15th stimulus when compared with the corresponding EPSC amplitude in control conditions at 100 and $200 \mathrm{~Hz}$. For example, EPSC ${ }_{15}$ was enhanced by $140 \pm 20 \%(n=13 ; 100 \mathrm{~Hz})$ and $260 \pm 80 \%(n=$ $11 ; 200 \mathrm{~Hz}$ ) of control, respectively ( $p \leq 0.03$, paired $t$ test, for both 100 and $200 \mathrm{~Hz}$ ). Thus, at high-frequency retinal fiber stimulation, presynaptic serotonergic inhibition increased the peak EPSC amplitude in response to later stimuli in the train.

The overlaid traces in Figure 4 also revealed another change in the synaptic response to trains by serotonergic presynaptic modulation. The time course of EPSC decay $(\tau)$ accelerated in the presence of 5-CT. The difference in the decay can be most clearly observed after the last EPSC in the train $\left(\mathrm{EPSC}_{15}\right.$ ) when the decay is fit by a double exponential function. On average, 5-CT significantly accelerated the slow component of $\operatorname{EPSC}_{15}$ decay $\left(\tau_{\mathrm{s}}\right)$ at $100 \mathrm{~Hz}$ (control, $\tau_{\mathrm{s}}=129 \pm 28 \mathrm{msec}$, vs $5-\mathrm{CT}, \tau_{\mathrm{s}}=59 \pm 11 \mathrm{msec}$; $n=6 ; p=0.02$, paired $t$ test) but not at $10 \mathrm{~Hz}$ (control, $\tau_{\mathrm{s}}=27 \pm$ $12 \mathrm{msec}$, vs 5 -CT, $\tau_{\mathrm{s}}=14 \pm 3 ; n=7 ; p=0.3$, paired $t$ test). In both control and 5-CT conditions, the average time course of EPSC $_{15}$ decay at $100 \mathrm{~Hz}$ was prolonged when compared with the average time course of a single EPSC (control: first, $\tau_{\mathrm{s}}=22 \pm 6$ msec, $n=7$, vs 15 th, $\tau_{\mathrm{s}}=129 \pm 28 \mathrm{msec}, n=6, p=0.01$; 5 -CT: first, $\tau_{\mathrm{s}}=11 \pm 4 \mathrm{msec}, n=7$, vs $15 \mathrm{th}, \tau_{\mathrm{s}}=59 \pm 11 \mathrm{msec}, n=7$, $p \leq 0.01)$. Moreover, the average $\tau_{\mathrm{s}}$ of a single EPSC in control conditions was not significantly different from that in the presence of 5-CT ( $p=0.12$; paired $t$ test). Our data are consistent with a prolongation of EPSC decay time course during a train secondary to the accumulation of presynaptic residual calcium that results in enhanced delayed release and extended time course of transmitter in the synaptic cleft. The EPSC $_{15}$ decay time course is decreased in the presence of a presynaptic modulator that acts by inhibiting presynaptic calcium, such as 5-CT (Rahamimoff and Yaari, 1973; Delaney et al., 1989; Van Der Kloot and Molgo, 1993; Ravin et al., 1997; Atluri and Regehr, 1998; Brenowitz et al., 1998).

Does the 5-CT-mediated inhibition of the first EPSC amplitude and acceleration of the time course of EPSC decay balance its enhancement of subsequent EPSC amplitudes (EPSC $\left.{ }_{2-15}\right)$ during high-frequency trains? We compared the average total synaptic charge transferred in control conditions to that in 5-CT. For the examples shown in Figure $4 A-C$, the total synaptic charge $(Q)$ was 59,29 , and $21 \mathrm{pA}^{\star}$ sec for 10,100 , and $200 \mathrm{~Hz}$, respectively, in control conditions and 23,15 , and $16 \mathrm{pA}^{\star} \mathrm{sec}$ in the presence of 5-CT. Thus, at all frequencies tested, presynaptic serotonergic modulation resulted in a net decrease in the synaptic charge transferred. However, the relative decrease in synaptic charge was not constant over the frequency range $\left(Q_{\mathrm{CT}} / Q_{\mathrm{CONT}}\right.$ was 0.39 , 0.52 , and 0.76 , respectively, for 10,100 , and $200 \mathrm{~Hz}$ ). Figure $4 E$ compares the $Q_{\mathrm{CT}} / Q_{\mathrm{CONT}}$ from seven individual relay neurons at $10 \mathrm{~Hz}$ to that at $100 \mathrm{~Hz}$. The reduction of synaptic charge transferred was greater at low frequency compared with high frequencies for five of seven cells. On average, the $Q_{\mathrm{CT}} / Q_{\mathrm{CONT}}$ was $0.5 \pm$ 0.1 at $10 \mathrm{~Hz}$ and $0.7 \pm 0.1$ at $100 \mathrm{~Hz}(p<0.03$; paired $t$ test $)$. Thus, although the net synaptic charge was decreased in the presence of presynaptic serotonergic modulation, relief of synaptic depression contributed a frequency dependence to the inhibition of the total synaptic charge transferred at the retinogeniculate synapse.

To evaluate whether the effects of serotonergic modulation that we have characterized in regular trains of stimuli also apply to the synaptic response to irregular trains of stimuli that more closely resemble physiological presynaptic activity, retinal fibers were activated in a pattern that mimics the firing pattern of a 
Figure 4. Differential modulation of synaptic strength and charge transfer by $5-\mathrm{HT}_{1}$ receptor activation. $A-C$ show the synaptic response to trains of 15 stimuli at $10 \mathrm{~Hz}(A), 100 \mathrm{~Hz}(B)$, and $200 \mathrm{~Hz}$ ( $(C$. Representative synaptic responses are shown in control conditions (left, top panel) and in the presence of $50 \mathrm{~nm} 5-\mathrm{CT}$ (left, bottom panel) for each stimulation frequency. Right panels show control (black) and 5-CT (gray) traces overlaid and expanded to compare the amplitudes of the corresponding subsequent EPSCs after the first EPSC in the train (truncated) between control and in 5-CT. D, Summary of the relative changes in EPSC amplitudes during trains of stimuli at frequencies of $10 \mathrm{~Hz}$ (circles; $n=7$ cells), $20 \mathrm{~Hz}$ (open triangles; $n=13$ cells), $50 \mathrm{~Hz}$ (squares; $n=13$ cells), $100 \mathrm{~Hz}$ (diamonds; $n=15$ cells), and $200 \mathrm{~Hz}$ (filled triangles; $n=11$ cells). The average ratio of the amplitude of each EPSC in 5-CT to the corresponding EPSC in control conditions (EPSC $\mathrm{CTTN}_{\mathrm{N})} / \mathrm{EPSC}_{\mathrm{CONT}(\mathrm{N})}$ ) is plotted as a function of stimulus number. Evoked synaptic current amplitudes were measured as the difference in the synaptic current between the baseline current immediately after the stimulus artifact and the peak of the corresponding EPSC. The relative changes in amplitudes of EPSC $_{2-15}$ in 5 -CT at 10 versus $200 \mathrm{~Hz}$ are significantly different $(p \leq 0.05)$. E, The relative reduction of synaptic charge $\left(Q_{\mathrm{CT}} / Q_{\text {CONT }}\right)$ at $10 \mathrm{~Hz}$ stimulation to that at $100 \mathrm{~Hz}$ stimulation is compared for seven individual relay cells. Bath temperature, $34-36^{\circ} \mathrm{C}$.

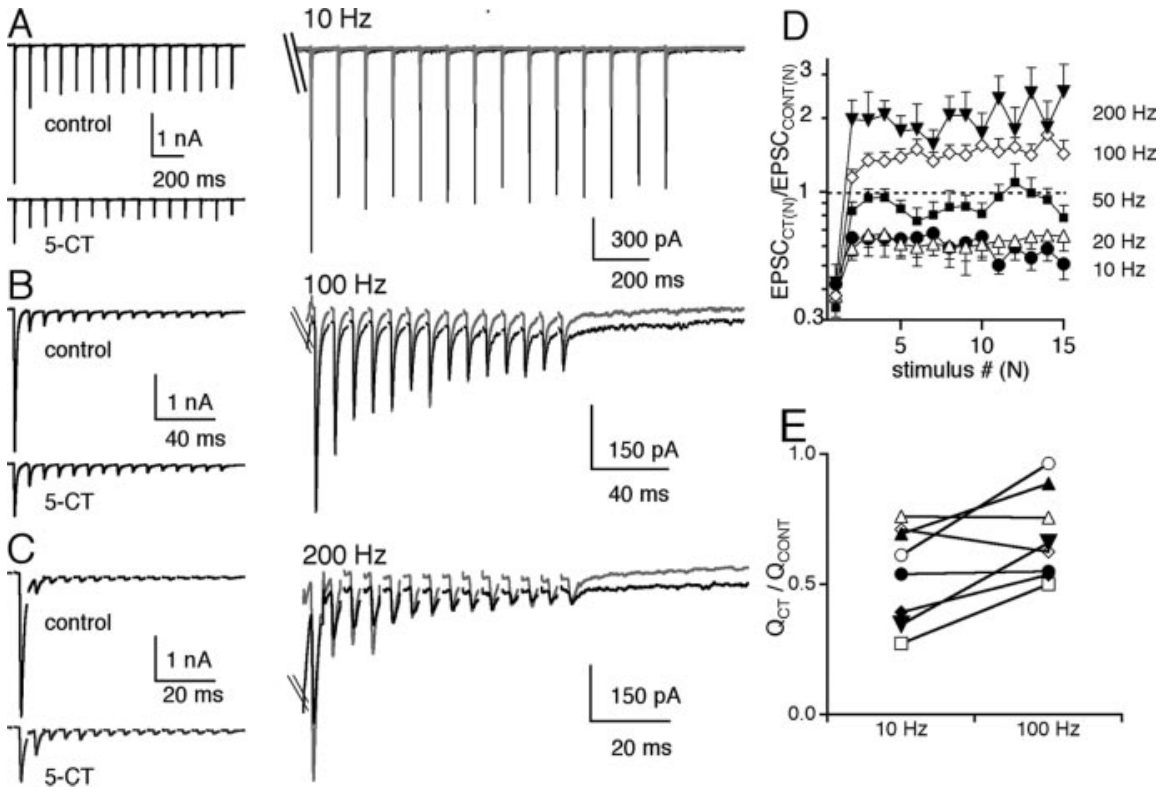

\section{5-HT $\mathrm{H}_{1}$ receptor-mediated effects on postsynaptic firing}

How do the decrease in synaptic charge and the relief of synaptic depression affect postsynaptic firing? If the safety factor at the retinogeniculate synapse is very high, such that individual EPSCs in a train inhibited by 5-CT can still drive the postsynaptic cell to fire, then one would expect firing to be enhanced for higher frequencies because of the strong relief of synaptic depression. Alternatively, if individual synaptic responses to retinal fiber stimulation are too weak to depolarize the postsynaptic neuron to threshold alone, then firing will depend more on the summation of EPSCs or the total synaptic charge transferred. To address this question, we examined the effects of 5-CT on the firing response of relay neurons to a physiological train of retinal fiber stimulation (see Experimental procedures). Because serotonin has been shown to contribute to the transition from a hyperpolarized bursting mode to a more depolarized tonic firing mode in relay neurons, we compared the responses of relay cells at two membrane potential ranges, -75 to $-70 \mathrm{mV}$ and -60 to $-55 \mathrm{mV}$, chosen to simulate the membrane potential for bursting and tonic firing modes, respectively (Steriade et al., 1993, 1997; McCormick and Bal, 1994).

By switching from voltage-clamp to current-clamp modes while recording from the same cell, we could correlate the mouse retinal ganglion cell in response to a flash of light. Figure $5 A$ shows that 5-CT relieved synaptic depression for each EPSC during a train with respect to the amplitude of the first EPSC of the train and greatly reduced the overall variability in EPSC amplitude within the train. A summary of responses taken from several different cells $(n=7)$ before and during bath application of $50 \mathrm{~nm}$ 5-CT is shown in Figure 5B. The peak amplitude of each AMPAR EPSC in the train $\left(A_{\mathrm{N}}\right)$ was normalized to the amplitude of the first evoked EPSC in the train $\left(A_{\mathrm{N}} / A_{1}\right)$ for both the control condition (filled circles) and in the presence of 5-CT (open squares). The synaptic response to the fifth action potential of the train elicited the greatest amount of synaptic depression ( $9 \pm 1 \%$ of the first EPSC) under control conditions whereas, in the presence of 5-CT, this depression was significantly relieved to $36 \pm$ $6 \%$ of the initial EPSC ( $n=7 ; p=0.003$, paired $t$ test). When each EPSC amplitude of the train in control conditions and in 5-CT was plotted relative to the first control EPSC, we found that the EPSC amplitude during periods of high-frequency retinal fiber stimulation in the presence of 5-CT was significantly enhanced when compared with the corresponding control EPSC (Fig. 5C, inset). This is illustrated more clearly in Figure $5 D$ when the absolute EPSC amplitude in the presence of the serotonergic agonist is normalized to that of the corresponding control EPSC $\left(\% \mathrm{EPSC}_{\mathrm{CT}(\mathrm{N})} / \mathrm{EPSC}_{\mathrm{CONT}(\mathrm{N})}\right)$. Thus, in response to physiological stimulation patterns, presynaptic serotonergic modulation at the retinogeniculate synapse could relieve synaptic depression as well as enhance the synaptic response to high-frequency retinal fiber activity. synaptic response and firing probability from a given relay neuron. A representative experiment is shown in Figure $6 \mathrm{~A}$ in a counterclockwise direction. In voltage-clamp mode, the synaptic response elicited by a train of physiological stimuli using the $\mathrm{K}^{+}$-based internal solution was very similar to that using a CsF internal recording solution (compare Figs. $6 A i$, left, to $5 A$ ). The recording amplifier was switched to the current-clamp mode with a hyperpolarized holding potential (Fig. 6 Aii, left) and then the cell was depolarized to $-55 \mathrm{mV}$ (Figure 6 Aiii, left). 5-CT was then bath applied at a holding potential of $-55 \mathrm{mV}$ (Fig. 6 Aiii, right), and after the firing response had reached equilibrium (after $10 \mathrm{~min}$ ), the cell was hyperpolarized (Fig. 6 Aii, right). At the end of the experiment, the recording was then switched back to the voltage-clamp mode (Fig. $6 \mathrm{~A} i$, right) in the presence of the serotonergic receptor agonist to examine the degree of 5-CT inhibition on the synaptic currents. This experimental paradigm ensured that each retinal fiber stimulation resulted in a synaptic response and allowed us to compare the synaptic response to postsynaptic firing. Consistent with findings from previous studies, we found that, for a given retinal fiber train, the number of postsynaptic action potentials generated at a depolarized holding potential ( -60 to $-55 \mathrm{mV}$ ) was generally greater than the number of action potentials generated at more hyperpolarized potentials $(-75$ to $-70 \mathrm{mV})$. Moreover, the spiking activity observed at depolarized potentials followed the pattern of input stimuli more closely than the burst-like spiking observed at more hyperpolarized potentials (Guido et al., 1995; Sherman, 1996; Blitz and Regehr, 2003). 
Figure $6 B$ illustrates that 5 -CT inhibited relay neuron firing in a reversible manner. Representative traces of the firing response of a relay neuron to a physiological train of retinal fiber stimuli are shown before and during bath application of 5-CT as well as during washout of the 5-HT agonist in the presence of cyanopindolol at depolarized (Fig. $6 \mathrm{~B}$, left) and hyperpolarized (Fig. $6 C$, left) potentials, respectively. The time course of the experiment is shown on the right as a raster plot of relay neuron spikes. When 5-CT was applied to the bath solution, the number of evoked APs decreased at both holding potentials. This effect was readily reversible with bath application of cyanopindolol. Comparison of the effects of 5-CT on relay neuron firing revealed that the degree of spike inhibition was not dependent on relay neuron holding potential. 5-CT decreased the number of action potentials to $32.8 \pm$ $17.4 \%(n=5 ; p=0.02$, paired $t$ test $)$ and $52.4 \pm 8.3 \%(n=6 ; p=0.002$, paired $t$ test) of control spikes at depolarized and hyperpolarized holding potentials, respectively (inhibition at $-55 \mathrm{vs}-70 \mathrm{mV}$ not significantly different; $p=0.31$ ). Moreover, spike voltage threshold was not significantly altered by 5 -CT $(-52.9 \pm 0.4$ vs $-52.2 \pm 0.6 \mathrm{mV}$ for control and 5-CT, respectively; $n=21$ neurons; $p=0.1$, paired $t$ test).

To determine whether possible postsynaptic effects of 5-CT contributed to its inhibition of relay neuron firing, we examined the effects of the serotonergic receptor agonist on the postsynaptic membrane potential in the absence of the presynaptic input. Figure 7 illustrates the membrane potential response of a relay neuron to a series of current injections designed to mimic EPSPs before (black trace) and during (gray trace) bath application of $50 \mathrm{~nm}$ 5 -CT. The time course of membrane potential decay after five depolarizing current injections at $100 \mathrm{~Hz}$, characterized by a double exponential fit, was not significantly altered in the presence of 5-CT (control: $\tau_{\text {fast }}, 4 \pm 1 \mathrm{msec}, \tau_{\text {slow }}, 33 \pm 2 \mathrm{msec}$; 5 -CT: $\tau_{\text {fast }}$, $6 \pm 1 \mathrm{msec}, \tau_{\text {slow }}, 44 \pm 7 \mathrm{msec} ; n=4 ; p \geq 0.2$ for both time constants, paired $t$ test). In addition, comparison of the area underlying the membrane potential changes in response to current injections revealed no significant changes in the presence of the 5- $\mathrm{HT}_{1}$ receptor agonist (control, $0.35 \pm 0.07 \mathrm{mV}^{\star}$ sec; 5-CT, $0.41 \pm 0.09 \mathrm{mV}^{\star} \mathrm{sec} ; n=4 ; p=0.1$, paired $t$ test). These data are consistent with a presynaptic site of action of 5-CT that results in a decrease in the total synaptic charge transferred at the retinogeniculate synapse and concomitant inhibition of relay neuron firing.

\section{Serotonergic inhibition of relay neuron firing is frequency dependent}

During regular trains of stimulation, the decrease in the total synaptic charge transferred in the presence of 5-CT, when compared with control conditions, was greater for lower frequencies than for higher frequencies (Fig. $4 E$ ). To determine whether pre- synaptic serotonergic modulation of postsynaptic firing is also frequency dependent, we examined the response of the synapse before and during bath application of 5-CT over a range of stimulation frequencies. Again, the membrane potential of relay neurons was depolarized to a range between -60 and $-55 \mathrm{mV}$ to mimic the tonic mode of firing. Figure $8 \mathrm{~A}$ shows representative firing responses of relay neurons recorded before (left) and during bath application of 5-CT (right). The synaptic response of each cell was recorded in voltage clamp at the beginning and end of the experiment to ensure that each presynaptic stimulation elicited a synaptic response (Fig. 6A). As described previously, the firing response to trains of retinal fiber stimulation varied from cell to cell (Blitz and Regehr, 2003). Thus, we examined the relative change in firing in response to 5-CT. 5-CT reduced the firing of the postsynaptic cell when stimulated with a train of 15 stimuli at $10 \mathrm{~Hz}$, diminishing the number of action potential spikes to $35.8 \pm 11 \%(n=12$ cells $)$ of control. However, the inhibitory effect of 5-CT was significantly less at higher frequencies, reducing the number of spikes to $66.8 \pm 5 \%$ of control for $200 \mathrm{~Hz}$ trains $(n=15$ cells; $p=0.04)$. The fraction of action potentials elicited in the presence of 5-CT, relative to control conditions, is plotted as a function of retinal fiber stimulation frequency in Figure $8 B$. Thus, consistent with the frequencydependent decrease in synaptic charge, inhibition of relay neuron firing by presynaptic serotonergic modulation was also frequency dependent. 

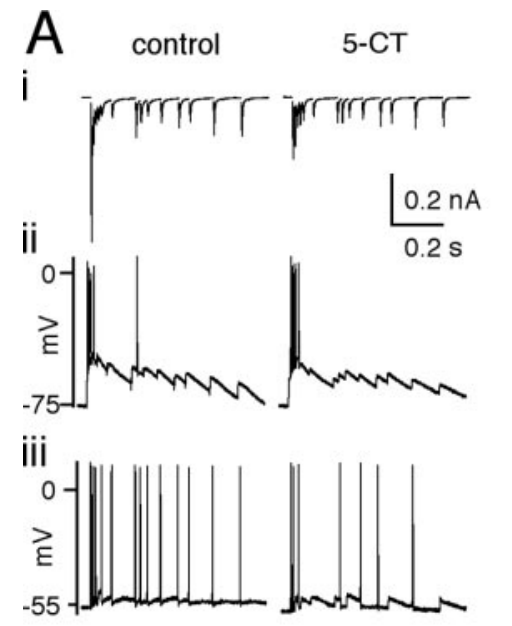

B
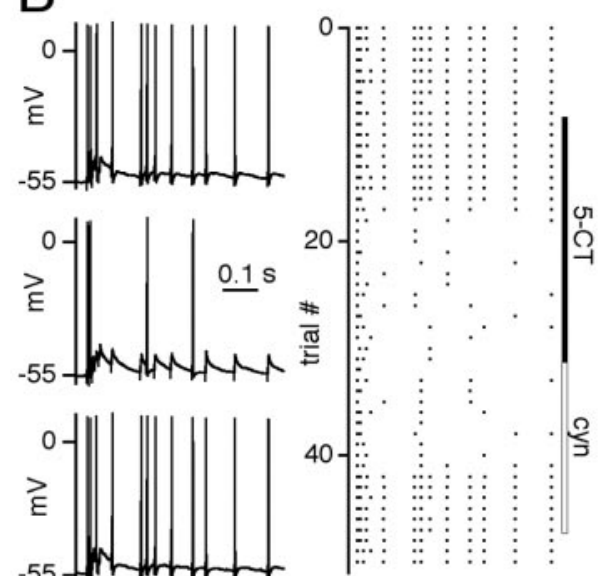

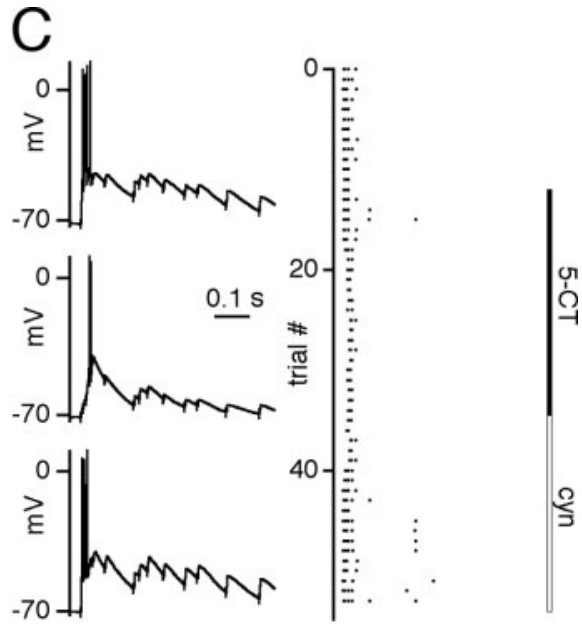

Figure 6. Activation of 5- $\mathrm{HT}_{1}$ receptor reversibly modulates the firing of geniculate neurons. $A$, Representative traces of geniculate neuron response in both voltage-clamp and current-clamp modes. Ai, Synaptic currents recorded under voltage-clamp mode in control condition (left) and in the presence of 5-CT (right) in response to a physiological pattern of stimulation. Aii, Aiii, Firing patterns of the same relay neuron under current-clamp mode at two different holding potentials are shown in the control conditions (left) and in the presence of $50 \mathrm{~nm} 5$-CT (right). $B$, $C$, Representative firing patterns of relay neurons in response to the physiological train of stimuli elicited at a holding potential of $-55 \mathrm{mV}(B)$ and $-70 \mathrm{mV}$ ( $C$ ). Traces are shown for control conditions (top) in the presence of 5 - СТ ( $50 \mathrm{~nm}$; middle) and during washout in the presence of the serotonergic antagonist cyanopindolol ( $5 \mu \mathrm{m}$; bottom). Raster plots on the right show the spike timing of the relay neurons. Stimulation trials are separated by $25 \mathrm{sec}$. Bath temperature, $34-36^{\circ} \mathrm{C}$.

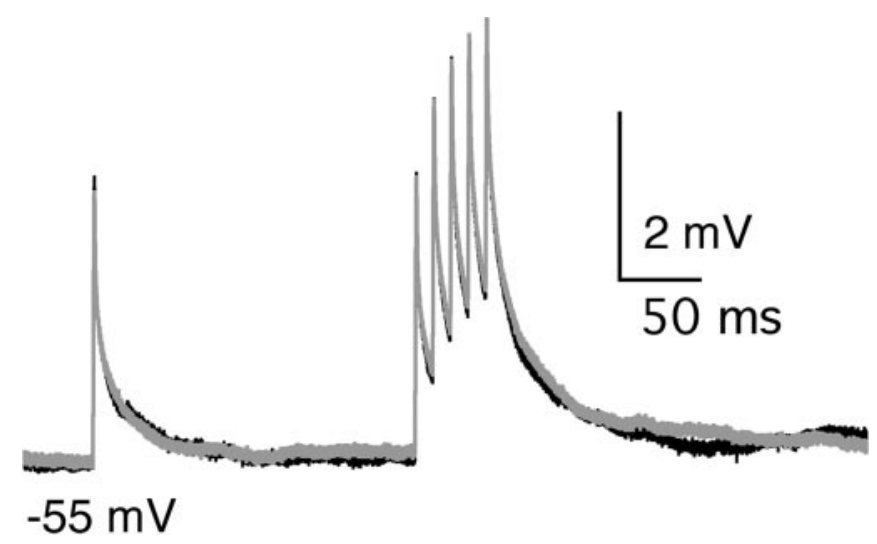

Figure 7. 5-CT does not alter postsynaptic membrane response to current injections. Short current ramps injections depolarized the membrane potential of a representative relay neuron. A single injection is followed by a $100 \mathrm{~Hz}$ train of five injections. The membrane potential response to this stimulation paradigm did not change after a $10-15 \mathrm{~min}$ bath application of 50 nм 5-CT. Bath temperature, $34-36^{\circ} \mathrm{C}$

\section{The role of baseline level of synaptic depression on presynaptic serotonergic modulation}

The stimulation paradigm that we used in the experiments shown in Figures 4 and 8 allows for complete recovery from synaptic depression between trials. This type of activity pattern would be consistent with the firing characteristics of several classes of RGCs in mice that have been shown to exhibit long periods of silence during darkness (ON cells) or light (OFF cells) (Pang et al., 2003). After a period without retinal ganglion cell spiking, the strength of the first retinogeniculate EPSC in response to a change in light stimulation would be much greater than the subsequent EPSCs and would thus contribute to a large portion of the total synaptic charge transferred from RGCs to relay neurons. We were also interested in understanding how presynaptic activity conditions that result in a baseline state of synaptic depression at the retinogeniculate synapse would influence 5-CT modulation of EPSC amplitudes and relay neuron firing. Thus, we first examined the effects of 5-CT on EPSC amplitude in response to a stimulation paradigm where a conditioning train of five stimuli at $50 \mathrm{~Hz}$ preceded different frequencies of retinal fiber trains. Fifty Hertz was selected because the amplitudes of the subsequent EPSCs after the first EPSC are similar between control conditions and in the presence of 5-CT (Fig. 4D). Figure 9A--C illustrates the synaptic response to a change in stimulus frequency from a baseline of $50 \mathrm{~Hz}$ to 15 stimuli at 10,50 , and $100 \mathrm{~Hz}$ for control conditions (top trace) and in the presence of 5-CT (bottom trace). On the right of each panel, synaptic currents in control conditions (black traces) and in the presence of 5-CT (gray traces) are overlaid to compare the amplitudes and time course of the EPSCs in response to the 15 stimuli after the conditioning train. Consistent with our previous data using regular trains, 5-CT enhanced the EPSC $_{2-15}$ amplitudes after the conditioning train at $100 \mathrm{~Hz}$ but reduced the amplitudes at $10 \mathrm{~Hz}$. A summary of the relative EPSC amplitude in the presence of 5-CT compared with the amplitude of the corresponding EPSC in control is shown in Figure 9D. However, when comparing the total synaptic charge transferred, measured from the onset of the train after the conditioning train, we found that synaptic charge is still reduced in the presence of 5-CT agonist (Fig. 9E). $Q_{\mathrm{CT}} / Q_{\mathrm{CONT}}$ was significantly greater at 100 versus $10 \mathrm{~Hz}$ for 10 individual cells (average $Q_{\mathrm{CT}} / Q_{\mathrm{CONT}}$ : for $10 \mathrm{~Hz}, 0.44 \pm 0.03$; for $100 \mathrm{~Hz}, 0.70 \pm 0.03$; $p \ll 0.001$, paired $t$ test). Thus, even when the amplitude of the first EPSC was not significantly larger than subsequent EPSCs in a train, the serotonergic agonist inhibited the total amount of charge. Comparison of the overlaid synaptic response in Figure $9 A-C$ (right) revealed the basis of the decrease in synaptic charge. Consistent with our data using regular trains (Fig. 4), 5-CT accelerated the decay of each EPSC in a train when compared with control conditions. However, the decrease in synaptic charge was frequency dependent, secondary to the enhancement of later EPSC amplitudes during high-frequency trains.

Figure 10 illustrates how the $50 \mathrm{~Hz}$ conditioning train affects relay neuron firing in the presence of 5-CT. The degree of inhibition of spiking by 5 -CT was significantly greater at 10 versus $100 \mathrm{~Hz}$ stimulation (Fig. $10 \mathrm{~B}$ ). In fact, relay neuron firing in response to $100 \mathrm{~Hz}$ retinal fiber stimulation was not significantly altered in 5-CT when compared with control conditions $(n=11$; 

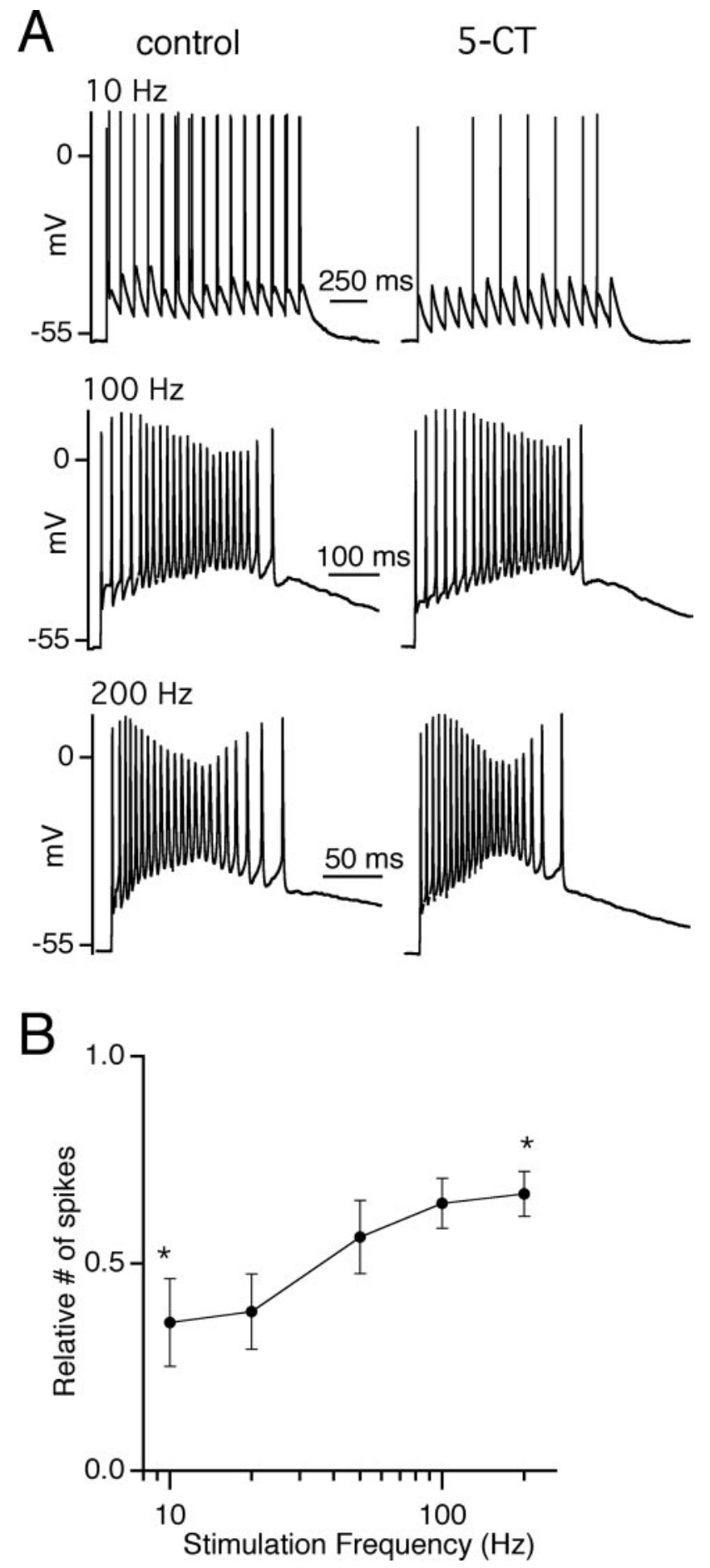

Figure 8. Activation of presynaptic $5-\mathrm{HT}_{1}$ receptor preferentially reduces the firing response of relay neurons to low-frequency stimulation. $A$, Representative traces from the same relay neuron in control conditions (left) and during bath application of $50 \mathrm{~nm} 5$ - CT (right) in response to a train of 15 stimuli at frequencies of $10 \mathrm{~Hz}$ (top), $100 \mathrm{~Hz}$ (middle), and $200 \mathrm{~Hz}$ (bottom). $B$, The ratio of spike number in the presence of 5 - $C \mathrm{~T}$ to control conditions is plotted as a function of stimulation frequency ( $n=12-16$ cells for each frequency). The asterisks indicate the reduction of firing in the presence of $5-\mathrm{CT}$ at 10 and $20 \mathrm{~Hz}$ is significantly different from that of 100 and $200 \mathrm{~Hz}$ ( $p<0.04$ for all 4 comparisons). Bath temperature, $34-36^{\circ} \mathrm{C}$.

$p=0.7$, paired $t$ test). The frequency dependence of inhibition by 5 -CT was steeper when there was a baseline level of depression at the retinogeniculate synapse.

To address whether a small change in postsynaptic $I_{\mathrm{h}}$ receptor conductance could contribute to the observed frequencydependent inhibition of relay neuron firing by 5-CT, we compared the firing of relay neurons in the presence of 5-CT (50 nM) to that after a $10 \mathrm{~min}$ bath application of 5-CT and the $I_{\mathrm{h}}$ receptor antagonist ZD7288 (10 $\mu \mathrm{M}$, a concentration that effectively inhibits the $I_{\mathrm{h}}$ current in our preparation as illustrated in Fig. $1 B$ ). We found that the addition of ZD7288 did not alter the frequency-dependent effects of 5-CT. The ratio of the number of spikes in 5-CT alone versus the number of spikes in 5-CT and 10 $\mu \mathrm{M}$ ZD7288 is $0.9 \pm 0.5,0.9 \pm 0.1$, and $0.9 \pm 0.1$ for 10,50 , and $100 \mathrm{~Hz}$, respectively ( $n=4$ and $p>0.4$ for all frequencies; paired $t$ test). Thus, the frequency dependence of the inhibition of relay neuron firing by 5 -CT is mediated through presynaptic and not postsynaptic modulatory effects of serotonin.

\section{Discussion}

Our pharmacological studies demonstrate that presynaptic $5 \mathrm{HT}_{1}$ receptors, especially that of the $5 \mathrm{HT}_{1 \mathrm{~B}}$ subtype, can exert a powerful inhibitory influence on glutamatergic transmission at the retinogeniculate synapse. These findings are consistent with the facts that RGCs express $5-\mathrm{HT}_{1 \mathrm{~B}}$ receptors in axon terminals of the LGN (Boschert et al., 1994) and that presynaptic inhibition through $5-\mathrm{HT}_{1 \mathrm{~B}}$ receptors occurs at other targets of RGCs, including the suprachiasmatic nucleus (Pickard et al., 1999) and the optic tectum (Mooney et al., 1994, 1996). Here, we take advantage of the relative selectivity of the 5- $\mathrm{HT}_{1}$ receptor agonist, 5-CT, for presynaptic over postsynaptic effects of serotonin to examine the role of presynaptic serotonergic modulation at the retinogeniculate synapse.

\section{Frequency-dependent relief from depression versus inhibition of synaptic strength}

This study demonstrates that, through inhibition of synaptic strength and a shortening of the decay time course of EPSCs, presynaptic modulation by serotonin results in a reduction of charge transferred across the retinogeniculate synapse. The acceleration of the EPSC decay by 5-CT is likely secondary to a reduction in the accumulation of presynaptic calcium, thus decreasing delayed release and transmitter accumulation in the synaptic cleft during prolonged trains (Atluri and Regehr, 1998). It is less likely that the change in the EPSC decay is secondary to the postsynaptic changes in intrinsic membrane properties because 5-CT did not significantly alter the membrane potential of the postsynaptic neuron (both from the resting potential as well as when the membrane potential was initially held at -55 $\mathrm{mV}$ ), the spike voltage threshold, or accelerate the membrane potential decay of relay neurons in response to intracellular current injections. Moreover, application of the $I_{\mathrm{h}}$ receptor antagonist, ZD7288, did not change the frequency-dependent effects of 5 -CT on relay neuron firing.

The serotonin-mediated decrease in total synaptic charge transferred across the retinogeniculate synapse results in a decrease in postsynaptic firing over a wide range of stimulation frequencies. However, counteracting this inhibitory serotonergic effect is a frequency-dependent relief from synaptic depression that, at higher stimulation frequencies, enhances the charge transfer, relative to lower frequencies, at the retinogeniculate synapse. The mechanisms underlying relief from depression most likely involve a calcium-mediated decrease in release probability that reduces the depletion of available vesicles, although we cannot rule out that other presynaptic processes, such as relief of G-protein-coupled receptor activation, may also play a role (Park 

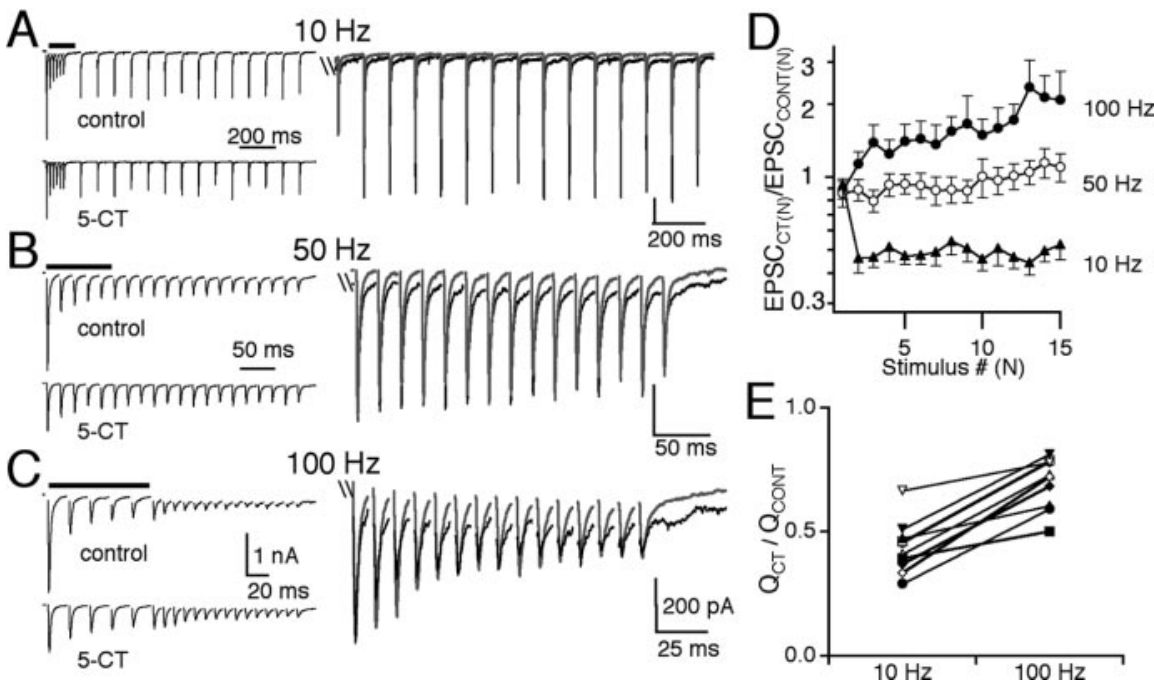

Figure 9. Frequency-dependent modulation of synaptic charge by $5-C T$ is present during prolonged stimulation. $A-C$, Representative traces of the synaptic response to trains of 15 stimuli at $10 \mathrm{~Hz}(A), 50 \mathrm{~Hz}(B)$, and $100 \mathrm{~Hz}(C$ ) after five conditioning stimuli at $50 \mathrm{~Hz}$. At each frequency, synaptic responses are shown in control conditions (left, top panel) and in the presence of $50 \mathrm{~nm} 5-\mathrm{CT}$ (left, bottom panel). The black bars over the traces indicate the time of the $50 \mathrm{~Hz}$ conditioning stimulation. Control (black) and 50 nм 5-CT (gray) traces are overlaid and expanded in $A-C$ (right panels) to compare the amplitudes and time course of the last 15 EPSCs following the conditioning stimuli (data not shown). Vertical calibration bar, $200 \mathrm{pA}$. D, Summary of the relative changes in EPSC amplitudes during trains of stimuli at frequencies of $10 \mathrm{~Hz}$ (triangles), $50 \mathrm{~Hz}$ (open circles), and $100 \mathrm{~Hz}$ (filled circles) $(n=7)$. The average ratio of EPSC amplitude in 5-CT to that in control conditions (EPSC $\left.\mathrm{CT}_{\mathrm{TN})} / \mathrm{EPSC}_{\mathrm{CONT}(\mathrm{N})}\right)$ is plotted as a function of stimulus number. The difference of the average EPSC ratios between 10 and $100 \mathrm{~Hz}$ is statistically significant from stimulus $2-15$ ( $p \leq$ $0.05)$. E, Comparison of the relative changes in synaptic charge $\left(Q_{\mathrm{CT}} / Q_{\text {CONT }}\right)$ from 10 individual cells are plotted for 10 and $100 \mathrm{~Hz}$. Bath temperature, $34-36^{\circ} \mathrm{C}$.

and Dunlap, 1998; Zucker and Regehr, 2002; Chen and Regehr, 2003).

Experiments using more prolonged stimulation trains, where a baseline level of synaptic depression is present, illustrate that presynaptic serotonergic modulation still results in a net decrease in synaptic charge, even when the first EPSC of the train is not dramatically reduced by 5 -CT. Together, our data indicate that, although the overall effect of presynaptic serotonergic modulation is inhibitory, relief from depression adds a frequency dependence to this inhibition so that information encoded in highfrequency retinal ganglion cell firing is more likely to be transmitted at the retinogeniculate synapse than that encoded in low-frequency spiking.

\section{Comparison of presynaptic modulation in the visual system to the auditory system}

The effects of presynaptic modulation at the retinogeniculate synapse differ from that of another sensory synapse, the end-bulb synapse of the chick nucleus magnocellularis. At this auditory synapse, presynaptic modulation by the $\mathrm{GABA}_{\mathrm{B}}$ agonist, baclofen, decreases synaptic strength and relieves synaptic depression, resulting in little effect on firing at low frequencies while enhancing postsynaptic firing at high stimulation frequencies (Otis and Trussell, 1996; Brenowitz et al., 1998a; Brenowitz and Trussell, 2001). These changes effectively extend the frequency range of presynaptic activity that is transmitted at the end-bulb synapse. In contrast, presynaptic serotonergic modulation of the retinogeniculate synapse reduces postsynaptic firing at lower more than at higher frequencies, thus limiting the frequency range of transmission.

One likely reason for the different outcome of presynaptic modulation between the two sensory synapses is the safety factor. At the end-bulb synapse, a single EPSC reduced to $10 \%$ of its initial strength could still reliably drive the firing of the postsynaptic nucleus magnocellularis cell (Brenowitz et al., 1998a). In contrast, at the retinogeniculate synapse, we found that synaptic inputs $>0.8$ and $0.4 \mathrm{nA}$ in amplitude were needed to elicit an action potential from holding potentials of -70 and $-55 \mathrm{mV}$, respectively, in thalamic relay neurons (data not shown). Because the average AMPAR EPSC evoked at $34-36^{\circ} \mathrm{C}$ in our experiments was $-2.2 \pm 0.3 \mathrm{nA}$ (ranging from -0.9 to $-5.7 \mathrm{nA} ; n=18$ ), the safety factor at the retinogeniculate synapse is significantly lower than that at the auditory synapse. Thus, single action potentials invading the presynaptic terminal of the retinogeniculate synapse are less likely to drive postsynaptic firing in the presence of 5-CT. Instead, temporal summation of EPSCs in a train is more important to the efficacy of transmission of visual information across the synapse. This is consistent with the in vivo finding that successive retinal spikes are more effective in driving relay neuron firing (Mastronarde, 1987; Usrey et al., 1998). Therefore, in addition to the presynaptic modulation of short-term plasticity, postsynaptic temporal summation in response to high-frequency retinal fiber stimulation must also contribute to the differential inhibition of low- versus high-frequency activity by serotonin.

The difference in the net effect of presynaptic modulation between the auditory and visual synapses highlights the fact that relief of depression that results in an enhancement of EPSC amplitudes during a train does not necessarily predict an enhancement of postsynaptic firing. The effects of presynaptic modulation can vary between different synapses, depending on the relative contributions of changes in synaptic strength, short-term synaptic plasticity, postsynaptic firing threshold and changes in delayed release and transmitter clearance in the synaptic cleft.

\section{Physiological significance of presynaptic modulation}

Serotonergic modulation has multiple effects at the retinogeniculate synapse. Counteracting the presynaptic $5 \mathrm{HT}_{1 \mathrm{~B}}$ receptormediated inhibition of neurotransmitter release is the activation of postsynaptic $I_{\mathrm{h}}$ current, resulting in elimination of spindle waves and rebound burst firing, thus increasing the probability of tonic mode firing (McCormick and Pape, 1990a; Lee and McCormick, 1996; Monckton and McCormick, 2002). However, we found that in both burst and tonic modes, relay neuron firing is reduced by presynaptic serotonergic modulation. Thus, in our recording conditions, the presynaptic inhibitory effect of serotonin can act in the presence of the postsynaptic excitatory effect. These findings are consistent with previous in vivo experiments that show that iontophoretic application of serotonin to the LGN or stimulation of the dorsal raphe nucleus decreases the firing rate of relay cells (Curtis and Davis, 1962; Rogawski and Aghajanian, 1980; Yoshida et al., 1984; Kayama, 1985; Marks et al., 1987; Funke and Eysel, 1993).

Inhibition of neurotransmission by serotonin may at first seem paradoxical, given that serotonergic tone is highest during the awake state and gradually declines through slow-wave sleep, 

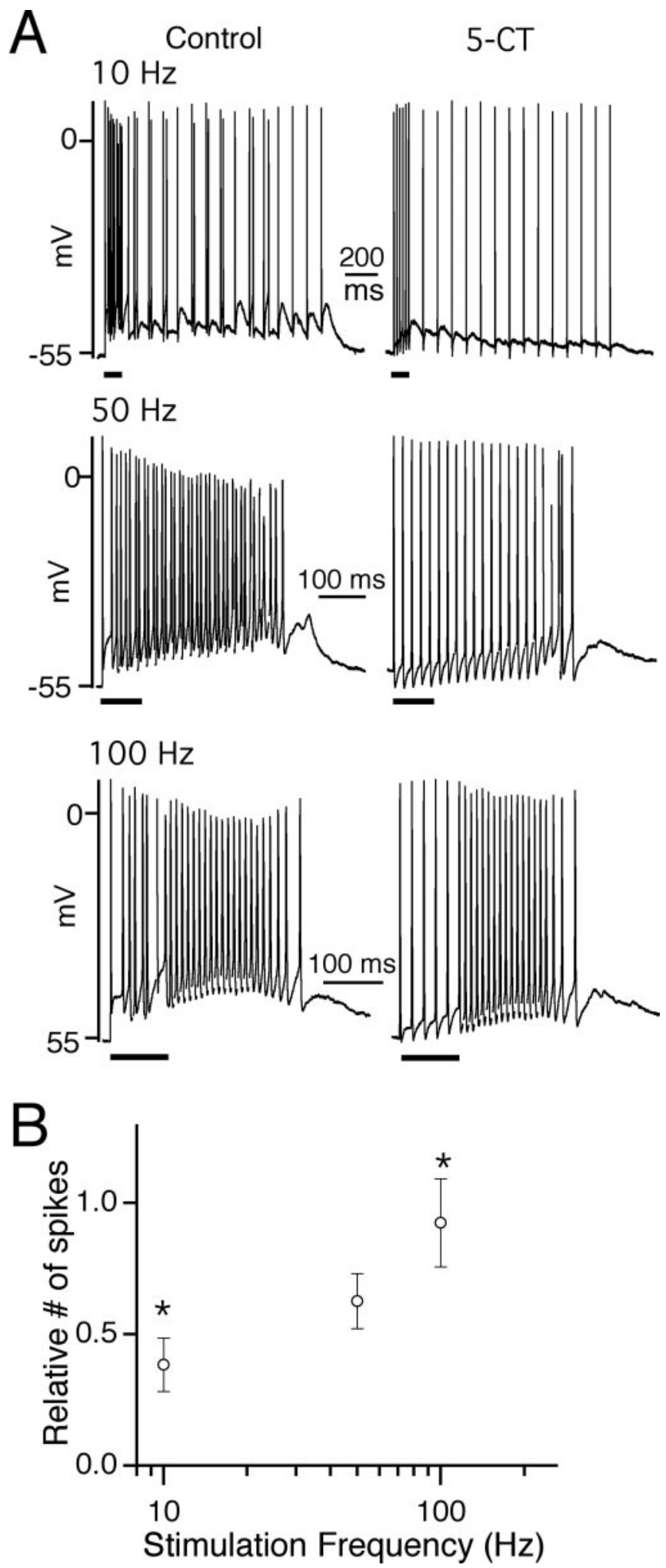

Figure 10. Differential inhibition of relay neuron firing by $5-\mathrm{CT}$ is also present at synapses with a recent history of activity. $A$, The firing responses of relay neurons to a train of 15 stimuliat $10 \mathrm{~Hz}$ (top), $50 \mathrm{~Hz}$ (middle), and $100 \mathrm{~Hz}$ (bottom) after five conditioning stimuli at $50 \mathrm{~Hz}$. Representative traces from the same neuron in control conditions (left) and during bath application of $50 \mathrm{~nm} 5-\mathrm{CT}$ (right). The black bars under each trace indicate the time of the conditioning stimuli. $B$, Summary of the ratio of spike number in response to the last 15 stimuli in the presence of 5 - $C T$ to that in control conditions is plotted as a function of stimulation frequency ( $n=10-11$ cells for each frequency). The asterisks indicate that inhibition at $10 \mathrm{~Hz}$ is significantly different from that of $100 \mathrm{~Hz}(p=0.008)$. Bath temperature, $34-36^{\circ} \mathrm{C}$. reaching a minimum during rapid eye movement states (Jacobs and Fornal, 1999). This raises the question of how presynaptic serotonergic modulation contributes to the transfer of information from the retina to the cortex. One possible explanation may lie in the frequency dependence of presynaptic inhibition. RGCs in mice have been shown to fire at rates ranging from 200 to 500 $\mathrm{Hz}$ in response to transitions between light and dark (Stone and Pinto, 1993; Nirenberg and Meister, 1997). Here, we show that activation of presynaptic $5-\mathrm{HT}_{1}$ receptors acts to preferentially favor the transmission of higher versus lower frequency RGC firing via the retinogeniculate synapse. By effectively limiting the relay of visual information to those RGCs that respond to a change in light stimuli with a robust discharge of action potentials, presynaptic serotonergic modulation may be one mechanism that improves the "signal-to-noise" of the transmitted information. Changes between the tonic and burst modes, as well as postsynaptic modulatory actions of neurotransmitters, have been shown previously to affect relay neuron "filtering" properties at other thalamic synapses (Mukherjee and Kaplan, 1995; CastroAlamancos and Calcagnotto, 2001; Castro-Alamancos, 2002). Here, we show that presynaptic inhibition can also strongly affect the temporal response properties of a thalamic synapse.

Our data does not address the possibility that serotonergic modulation takes place at other locations in the LGN. In fact, previous studies have shown an inhibitory serotonergic effect in the LGN through excitation of GABAergic neurons of the perigeniculate nucleus (McCormick and Wang, 1991; Funke and Eysel, 1993), GABAergic interlaminar interneurons (Sanchez-Vives et al., 1996), and through mild excitation of local GABAergic interneurons (Pape and McCormick, 1995). The inhibitory circuitry has been shown to contribute to the center-surround antagonism of receptive fields of LGN neurons (Eysel et al., 1986; Norton et al., 1989; Fjeld et al., 2002).

We studied the modulatory role of serotonin at the retinogeniculate synapse in isolation from GABAergic inhibitory influences, ascending brainstem connections, and corticothalamic feedback projections that have all been shown to be important in thalamic processing of visual information (McCormick and Bal, 1994, 1997; Steriade et al., 1997). This reductionist approach allowed us to examine the contributions of serotonergic presynaptic modulation at the excitatory retinogeniculate connection. In the LGN of intact, awake animals, however, it is likely that the presynaptic and postsynaptic effects of serotonin at the retinogeniculate synapse work in concert with other neuromodulators, as well as with inhibitory and cortical feedback circuits to refine the thalamic relay neuron response to visual information.

\section{References}

Atluri PP, Regehr WG (1998) Delayed release of neurotransmission from cerebellar granule cells. J Neurosci 18:8214-8227.

Baxter G, Kennett G, Blaney F, Blackburn T (1995) 5-HT2 receptor subtypes: a family re-united? Trends Pharmacol Sci 16:105-110.

Blitz D, Regehr WG (2003) Retinogeniculate synaptic properties controlling spike number and timing in relay neurons. J Neurophysiol 90:2438-2450.

Boschert U, Amara DA, Segu L, Hen R (1994) The mouse 5-hydroxytryptamine ${ }_{1 \mathrm{~B}}$ receptor is localized predominantly on axon terminals. Neuroscience 58:167-182.

Brenowitz S, Trussell LO (2001) Minimizing synaptic depression by control of release probability. J Neurosci 21:1857-1867.

Brenowitz S, David J, Trussell L (1998) Enhancement of synaptic efficacy by presynaptic $\mathrm{GABA}_{\mathrm{B}}$ receptors. Neuron 20:135-141.

Castro-Alamancos MA (2002) Properties of primary sensory (lemniscal) synapses in the ventrobasal thalamus and the relay of high-frequency sensory inputs. J Neurophysiol 87:946-953. 
Castro-Alamancos MA, Calcagnotto ME (2001) High-pass filtering of corticothalamic activity by neuromodulators released in the thalamus during arousal: in vitro and in vivo. J Neurophysiol 85:1489-1497.

Chen C, Regehr WG (2000) Developmental remodeling of the retinogeniculate synapse. Neuron 28:955-966.

Chen C, Regehr WG (2003) Presynaptic modulation of the retinogeniculate synapse. J Neurosci 23:3130-3135.

Chen C, Blitz DM, Regehr WG (2002) Contributions of receptor desensitization and saturation to plasticity at the retinogeniculate synapse. Neuron 33:779-788.

Curtis DR, Davis R (1962) Pharmacological studies upon neurones of the lateral geniculate nucleus of the cat. Br J Pharmacol 18:217-246.

Delaney KR, Zucker RS, Tank DW (1989) Calcium in motor nerve terminals associated with posttetanic potentiation. J Neurosci 9:3558-3567.

De Lima AD, Singer W (1987) The serotoninergic fibers in the dorsal lateral geniculate nucleus of the cat: distribution and synaptic connections demonstrated with immunocytochemistry. J Comp Neurol 258:339-351.

Dinopoulos A, Dori I, Parnavelas JG (1995) Serotonergic innervation of the lateral geniculate nucleus of the rat during postnatal development: a light and electron microscopic immunocytochemical analysis. J Comp Neurol 363:532-544.

Engel G, Gothert M, Hoyer D, Schlicker E, Hillenbrand K (1986) Identity of inhibitory presynaptic 5-hydroxytryptamine (5-HT) autoreceptors in the rat brain cortex with 5-HT1B binding sites. Naunyn-Schmiedebergs Arch Pharmacol 332:1-7.

Eysel UT, Pape HC, Van Schayck R (1986) Excitatory and differential disinhibitory actions of acetylcholine in the lateral geniculate nucleus of the cat. J Physiol (Lond) 370:233-254.

Fjeld IT, Ruksenas O, Heggelund P (2002) Brainstem modulation of visual response properties of single cells in the dorsal lateral geniculate nucleus of cat. J Physiol (Lond) 543:541-554.

Funke K, Eysel UT (1993) Modulatory effects of acetylcholine, serotonin and noradrenaline on the activity of cat perigeniculate neurons. Exp Brain Res 95:409-420.

Gerard C, Martres MP, Lefevre K, Miquel MC, Verge D, Lanfumey L, Doucet E, Hamon M, el Mestikawy S (1997) Immuno-localization of serotonin 5-HT6 receptor-like material in the rat central nervous system. Brain Res 746:207-219.

Glennon RA, Hong SS, Bondarev M, Law H, Dukat M, Rakhi S, Power P, Fan E, Kinneau D, Kamboj R, Teitler M, Herrick-Davis K, Smith C (1996) Binding of $O$-alkyl derivatives of serotonin at human $5-\mathrm{HT} 1 \mathrm{D} b$ receptors. J Med Chem 39:314-322.

Guido W, Lu SM, Vaughan JW, Godwin DW, Sherman SM (1995) Receiver operating characteristic (ROC) analysis of neurons in the cat's lateral geniculate nucleus during tonic and burst response mode. Vis Neurosci 12:723-741

Gustafson EL, Durkin MM, Bard JA, Zgombick J, Branchek TA (1996) A receptor autoradiographic and in situ hybridization analysis of the distribution of the 5-ht7 receptor in rat brain. Br J Pharmacol 117:657-666.

Guzman-Marin R, Alam M, Szymusiak R, Drucker-Colin R, Gong H, McGinty D (2000) Discharge modulation of rat dorsal raphe neurons during sleep and waking: effects of preoptic/basal forebrain warming. Brain Res 875:23-34.

Jacobs BL, Fornal CA (1999) Activity of serotonergic neurons in behaving animals. Neuropsychopharmacology 21:9S-15S.

Kayama Y (1985) Ascending, descending and local control of neuronal activity in the rat lateral geniculate nucleus. Vision Res 25:339-347.

Kayama Y, Shimada S, Hishikawa Y, Ogawa T (1989) Effects of stimulating the dorsal raphe nucleus of the rat on neuronal activity in the dorsal lateral geniculate nucleus. Brain Res 489:1-11.

Kia HK, Miquel MC, Brisorgueil MJ, Daval G, Riad M, El Mestikawy S, Hamon M, Verge D (1996) Immunocytochemical localization of serotonin $_{1 \mathrm{~A}}$ receptors in the rat central nervous system. J Comp Neurol 365:289-305.

Lee KH, McCormick DA (1996) Abolition of spindle oscillations by serotonin and norepinephrine in the ferret lateral geniculate and perigeniculate nuclei in vitro. Neuron 17:309-321.

Lopez-Gimenez JF, Mengod G, Palacios JM, Vilaro MT (2001a) Regional distribution and cellular localization of 5-HT2C receptor mRNA in monkey brain: comparison with $[3 \mathrm{H}]$ mesulergine binding sites and choline acetyltransferase mRNA. Synapse 42:12-26.

Lopez-Gimenez JF, Vilaro MT, Palacios JM, Mengod G (2001b) Mapping of
5-HT2A receptors and their mRNA in monkey brain: [3H]MDL100,907 autoradiography and in situ hybridization studies. J Comp Neurol 429:571-589.

Lydic R, McCarley RW, Hobson JA (1983) The time-course of dorsal raphe discharge, PGO waves, and muscle tone averaged across multiple sleep cycles. Brain Res 274:365-370.

Marks GA, Speciale SG, Cobbey K, Roffwarg HP (1987) Serotonergic inhibition of the dorsal lateral geniculate nucleus. Brain Res 418:76-84.

Mastronarde DN (1987) Two classes of single-input X-cells in cat lateral geniculate nucleus. II. Retinal inputs and the generation of receptive-field properties. J Neurophysiol 57:381-413.

McCormick DA (1992a) Neurotransmitter actions in the thalamus and cerebral cortex and their role in neuromodulation of thalamocortical activity. Prog Neurobiol 39:337-388.

McCormick DA (1992b) Neurotransmitter actions in the thalamus and cerebral cortex. J Clin Neurophysiol 9:212-223.

McCormick DA, Bal T (1994) Sensory gating mechanisms of the thalamus. Curr Opin Neurobiol 4:550-556.

McCormick DA, Bal T (1997) Sleep and arousal: thalamocortical mechanisms. Annu Rev Neurosci 20:185-215.

McCormick DA, Pape HC (1990a) Noradrenergic and serotonergic modulation of a hyperpolarization-activated cation current in thalamic relay neurones. J Physiol (Lond) 431:319-342.

McCormick DA, Pape HC (1990b) Properties of a hyperpolarizationactivated cation current and its role in rhythmic oscillation in thalamic relay neurones. J Physiol (Lond) 431:291-318.

McCormick DA, Wang Z (1991) Serotonin and noradrenaline excite GABAergic neurones of the guinea-pig and cat nucleus reticularis thalami. J Physiol (Lond) 442:235-255.

McGinty DJ, Harper RM (1976) Dorsal raphe neurons: depression of firing during sleep in cats. Brain Res 101:569-575.

Middlemiss DN, Fozard JR (1983) 8-Hydroxy-2-(di-n-propylamino)tetralin discriminates between subtypes of the 5-HT1 recognition site. Eur J Pharmacol 90:151-153.

Monckton JE, McCormick DA (2002) Neuromodulatory role of serotonin in the ferret thalamus. J Neurophysiol 87:2124-2136.

Mooney RD, Shi MY, Rhoades RW (1994) Modulation of retinotectal transmission by presynaptic $5-\mathrm{HT}_{1 \mathrm{~B}}$ receptors in the superior colliculus of the adult hamster. J Neurophysiol 72:3-13.

Mooney RD, Huang X, Shi MY, Bennett-Clarke CA, Rhoades RW (1996) Serotonin modulates retinotectal and corticotectal convergence in the superior colliculus. Prog Brain Res 112:57-69.

Mukherjee P, Kaplan E (1995) Dynamics of neurons in the cat lateral geniculate nucleus: in vivo electrophysiology and computational modeling. J Neurophysiol 74:1222-1243.

Nirenberg S, Meister M (1997) The light response of retinal ganglion cells is truncated by a displaced amacrine circuit. Neuron 18:637-650.

Norton TT, Holdefer RN, Godwin DW (1989) Effects of bicuculline on receptive field center sensitivity of relay cells in the lateral geniculate nucleus. Brain Res 488:348-352.

Otis TS, Trussell LO (1996) Inhibition of transmitter release shortens the duration of the excitatory synaptic current at a calyceal synapse. J Neurophysiol 76:3584-3588.

Pang JJ, Gao F, Wu SM (2003) Light-evoked excitatory and inhibitory synaptic inputs to ON and OFF alpha ganglion cells in the mouse retina. J Neurosci 23:6063-6073.

Papadopoulos GC, Parnavelas JG (1990) Distribution and synaptic organization of serotoninergic and noradrenergic axons in the lateral geniculate nucleus of the rat. J Comp Neurol 294:345-355.

Pape HC, McCormick DA (1989) Noradrenaline and serotonin selectively modulate thalamic burst firing by enhancing a hyperpolarizationactivated cation current. Nature 340:715-718.

Pape HC, McCormick DA (1995) Electrophysiological and pharmacological properties of interneurons in the cat dorsal lateral geniculate nucleus. Neuroscience 68:1105-1125.

Park D, Dunlap K (1998) Dynamic regulation of calcium influx by G-proteins, action potential waveform, and neuronal firing frequency. J Neurosci 18:6757-6766.

Pickard GE, Smith BN, Belenky M, Rea MA, Dudek FE, Sollars PJ (1999) $5-\mathrm{HT}_{1 \mathrm{~B}}$ receptor-mediated presynaptic inhibition of retinal input to the suprachiasmatic nucleus. J Neurosci 19:4034-4045.

Pompeiano M, Palacios JM, Mengod G (1994) Distribution of the serotonin 
5-HT2 receptor family mRNAs: comparison between 5-HT2A and 5-HT2C receptors. Brain Res Mol Brain Res 23:163-178.

Rahamimoff R, Yaari Y (1973) Delayed release of transmitter at the frog neuromuscular junction. J Physiol (Lond) 228:241-257.

Ravin R, Spira ME, Parnas H, Parnas I (1997) Simultaneous measurement of intracellular $\mathrm{Ca}^{2+}$ and asynchronous transmitter release from the same crayfish bouton. J Physiol (Lond) 501 2:251-262.

Richardson BP, Engel G, Donatsch P, Stadler PA (1985) Identification of serotonin M-receptor subtypes and their specific blockade by a new class of drugs. Nature 316:126-131.

Rogawski MA, Aghajanian GK (1980) Norepinephrine and serotonin: opposite effects on the activity of lateral geniculate neurons evoked by optic pathway stimulation. Exp Neurol 69:678-694.

Sanchez-Vives MV, Bal T, Kim U, von Krosigk M, McCormick DA (1996) Are the interlaminar zones of the ferret dorsal lateral geniculate nucleus actually part of the perigeniculate nucleus? J Neurosci 16:5923-5941.

Sari Y, Miquel MC, Brisorgueil MJ, Ruiz G, Doucet E, Hamon M, Verge D (1999) Cellular and subcellular localization of 5-hydroxytryptamine1B receptors in the rat central nervous system: immunocytochemical, autoradiographic and lesion studies. Neuroscience 88:899-915.

Schlicker E, Werner U, Hamon M, Gozlan H, Nickel B, Szelenyi I, Gothert M (1992) Anipirtoline, a novel, highly potent 5-HT1B receptor agonist with antinociceptive/antidepressant-like actions in rodents. Br J Pharmacol 105:732-738.
Sherman SM (1996) Dual response modes in lateral geniculate neurons: mechanisms and functions. Vis Neurosci 13:205-213.

Steriade M, McCormick DA, Sejnowski TJ (1993) Thalamocortical oscillations in the sleeping and aroused brain. Science 262:679-685.

Steriade M, Jones EG, McCormick DA (1997) Thalamus. Oxford: Elsevier.

Stone C, Pinto LH (1993) Response properties of ganglion cells in the isolated mouse retina. Vis Neurosci 10:31-39.

Upton AL, Salichon N, Lebrand C, Ravary A, Blakely R, Seif I, Gaspar P (1999) Excess of serotonin (5-HT) alters the segregation of ipsilateral and contralateral retinal projections in monoamine oxidase A knock-out mice: possible role of 5-HT uptake in retinal ganglion cells during development. J Neurosci 19:7007-7024.

Usrey WM, Reppas JB, Reid RC (1998) Paired-spike interactions and synaptic efficacy of retinal inputs to the thalamus. Nature 395:384-387.

Van Der Kloot W, Molgo J (1993) Facilitation and delayed release at $\sim 0^{\circ} \mathrm{C}$ at the frog neuromuscular junction: effects of calcium chelators, calcium transport inhibitors, and okadaic acid. J Neurophysiol 69:717-729.

Wood M, Chaubey M, Atkinson P, Thomas DR (2000) Antagonist activity of meta-chlorophenylpiperazine and partial agonist activity of $8-\mathrm{OH}-$ DPAT at the 5-HT(7) receptor. Eur J Pharmacol 396:1-8.

Yoshida M, Sasa M, Takaori S (1984) Serotonin-mediated inhibition from dorsal raphe nucleus of neurons in dorsal lateral geniculate and thalamic reticular nuclei. Brain Res 290:95-105.

Zucker RS, Regehr WG (2002) Short-term synaptic plasticity. Annu Rev Physiol 64:355-405. 